\title{
Synthesis of a 10,000-Membered Library of Molecules Resembling Carpanone and Discovery of Vesicular Traffic Inhibitors
}

\author{
Brian C. Goess ${ }^{\dagger}$, Rami N. Hannoush, Lawrence K. Chan, Tomas Kirchhausen*, and Matthew \\ D. Shair \\ Contribution from the Department of Chemistry \& Chemical Biology, HarVard University, \\ Cambridge, Massachusetts 02138, Harvard Institute of Chemistry \& Cell Biology, Harvard Medical \\ School, Boston, Massachusetts 02115, and the Department of Cell Biology and the CBR Institute \\ for Biomedical Research, Harvard Medical School, 200 Longwood Avenue, Boston, Massachusetts \\ 02115
}

\begin{abstract}
Split-and-pool synthesis of a 10,000-membered library of molecules resembling the natural product carpanone has been achieved. The synthesis features development of solid-phase multicomponent reactions between nitrogen nucleophiles, enones, and hydroxylamines, and a solid-phase application of the Huisgen cycloaddition affording substituted triazoles. The synthesis was performed in highcapacity $(500 \mu \mathrm{m})$ polystyrene beads using a one bead-one stock solution strategy that enabled phenotypic screens of the resulting library. Using whole-cell fluorescence imaging, we discovered a series of molecules from the carpanone-based library that inhibit exocytosis from the Golgi apparatus. The most potent member of this series has an $\mathrm{IC}_{50}$ of $14 \mu \mathrm{M}$. We also report structureactivity relationships for the molecules exhibiting this interesting phenotype. These inhibitors of exocytosis may be useful reagents for the study of vesicular traffic.
\end{abstract}

\section{Introduction}

Natural products and their derivatives serve as medicines and as probes of complex biological processes. For example, rapamycin is being used to elucidate the role of mTOR (mammalian target of rapamycin), ${ }^{1}$ and brefeldin $\mathrm{A},{ }^{2}$ a unique inhibitor of the GTPase Arf1, is a valuable reagent for studying vesicular traffic (Chart 1). Many medicines are themselves natural products (erythromycin, ${ }^{3}$ taxol, ${ }^{4}$ and lovastatin ${ }^{5}$ ) or are derived from natural products (aspirin).

Recently, there has been an effort to determine whether molecules generated through diversityoriented synthesis (DOS) might serve, as natural products do, as useful probes of biological processes or as lead structures for medicines. ${ }^{6}$ Advantages of molecules derived from DOS over those derived from natural sources include the following: (1) they can be generated in a format more amenable to high-throughput biological screens; and (2) the structures of compounds entering screens can be controlled, allowing planned experimentation to determine which structures are most active and which substructures contribute most to overall activity. However, one major difference between molecules derived from DOS and those derived from natural sources is that natural products may be exposed to the pressures of evolution (mutation,

E-mail: shair@chemistry.harvard.edu.

${ }^{\dagger}$ Present address: Furman University, Greenville, SC.

Supporting Information Available: Complete experimental procedures for the preparation of compounds 8-18 and $\mathbf{2 4 - 4 7}$ with characterization data, and detailed procedures for library synthesis and biological screens. ${ }^{1} \mathrm{H}$ NMR, ${ }^{13} \mathrm{C}$ NMR, and IR spectra and LR/ HRMS data for compounds 8-18, 24-41, CLL-8, and CLL-19. GC and LC-MS quality control spectra for 8 final library members (PDF). This material is available free of charge via the Internet at http://pubs.acs.org. 
selection, and amplification), leading to molecules that provide some advantage to the producing organisms. ${ }^{7}$ This means that certain natural products are more likely to be, for example, high affinity binders to their protein targets than are molecules generated via DOS.

We have decided to construct DOS libraries around core structures that are based directly on natural product structures. ${ }^{8}$ Our hypothesis is that library members with such core structures will have a higher intrinsic ability to bind proteins than would library members with core structures that are not based directly on natural product structures. Furthermore, natural products offer the opportunity to use biomimetic synthesis as a strategy for rapid assembly of their complex structures. ${ }^{9}$ It is important to distinguish our strategy, using natural productbased libraries to discover molecules with new biological functions, from the existing strategy of using natural product-based libraries to improve the properties of natural products. ${ }^{8}$

We demonstrated the successful application of this strategy in our recent discovery of secramine. We developed a biomimetic diversity-oriented synthesis of galanthamine-like molecules, screened these molecules in a fluorescence-based phenotypic screen, and discovered secramine, a cell-permeable inhibitor of vesicular traffic from the Golgi. ${ }^{10}$ Here we report the development, split-pool synthesis, and phenotypic screening of a 10,000-member encoded library of molecules based on the biomimetic synthesis of carpanone first reported by Chapman. ${ }^{11}$ Our synthesis features three-component conjugate addition reactions that may prove useful in other DOS projects. We screened the library in a fluorescence-based phenotypic assay and identified members of the library that inhibit vesicular traffic, and the results of this screen are described. The molecules discovered in this study may be useful reagents for studying vesicular traffic and the proteins involved in vesicular traffic.

\section{Results and Discussion}

Carpanone has a number of features that make it useful as a scaffold for split-and-pool library synthesis (Scheme 1): (1) carpanone possesses significant complexity (six rings and five contiguous stereocenters); (2) it is generated from easily prepared precursors in an efficient, single-step transformation ${ }^{11}$ that could potentially be adapted to the solid phase ${ }^{12}$ (3) its methyl substituents offer a handle for attachment to the solid phase; (4) carpanone contains an enone, a versatile functional group that could be transformed through split-and-pool synthesis in myriad ways $;{ }^{13}$ and (5) its rigid, cup-like shape should enable diastereoselective reactions from its convex face. ${ }^{14}$

Recently, we reported a solid-phase, biomimetic synthesis of carpanone-like molecules via the heterodimerization of electronically differentiated $o$-hydroxystyrenes (Scheme 2).${ }^{15}$ Electronrich $o$-hydroxystyrene 1, immobilized in polystyrene resin, was treated with electron-deficient $o$-hydroxystyrene $\mathbf{2}$ in solution, and, upon addition of iodobenzene diacetate $\left(\mathrm{PhI}-(\mathrm{OAc})_{2}\right)$, an oxidative coupling followed by an inverse-electron demand Diels-Alder reaction occurred to yield resin-bound heterodimer 3 . The ability to produce a carpanone-like heterodimer in the solid phase was significant not only because it demonstrated that the key carpanone dimerization reaction could be performed in resin, but it also transformed the dimerization reaction into a diversity-generating step. Thus, many scaffolds could be produced from the same resin-bound $o$-hydroxystyrene simply by varying the structure of the $o$-hydroxystyrene introduced in solution.

A screen of different linkers $\left(\mathrm{R}^{1}\right)$ and spacers $\left(\mathrm{R}^{2}\right)$ was conducted to optimize the yield of heterodimer 3 relative to $\mathbf{4}$, the undesired product of intra-resin homodimerization of $\mathbf{1}$. The optimal combination, depicted in Scheme 2, proved general. Five unique electron-deficient $o$ hydroxystyrenes were found to couple with $\mathbf{1}$ to yield resin-bound heterodimers that were isolated in $77-81 \%$ yield after cleavage from the resin. Analyses of the reaction products 
indicated that the only significant byproduct of these reactions was undesired homodimer $\mathbf{4}$, which was produced in $10-15 \%$ yield.

The presence of homodimer byproduct, however, complicated the use of this reaction as the basis for a split-and-pool library synthesis. At maximal resin loading levels of $\mathbf{1}(1.1 \mathrm{mmol} / \mathrm{g}$ resin), formation of homodimer 4 effectively suppressed heterodimerization. At a lower loading level of $\mathbf{1}(0.15 \mathrm{mmol} / \mathrm{g}$ resin), heterodimer $\mathbf{3}$ was favored over $\mathbf{4}$ by the ratio of 5.3:1, but this loading level was considered to be too low to support multiple biological screens using the ICCB ${ }^{16}$ standard protocols for library formatting and analysis. ${ }^{17}$ Furthermore, the unwanted homodimer present in each resin bead following oxidative coupling would be retained throughout the split-and-pool synthesis and would contaminate the stock solutions of final library compounds.

With these considerations in mind, we elected to use a homodimer similar to $\mathbf{4}$ as a scaffold for our library synthesis. This strategy offers several benefits over a heterodimeric library. A scaffold formed in a solid-phase homodimerization would not suffer from the impurity problems that plagued our heterodimeric scaffolds. Furthermore, loading levels could be significantly increased over those used for heterodimerizations since there would be no need to spatially separate the resin-bound substrates in order to minimize intra-bead homodimerization. ${ }^{18}$ Finally, the diethylsilyl linker and amide spacer, which were developed empirically solely to enhance selectivity for heterodimerization, could be replaced with a more robust diisopropylsilyl linker ${ }^{19}$ and an all-carbon spacer, thus simplifying resin preparation. The primary drawback to this approach is that, unlike the analogous situation with heterodimeric scaffolds, the dimerization reaction itself could not be used as a diversification step to yield multiple scaffolds ${ }^{20}$ since there is only one possible homodimer that can be formed from a resin-bound monomer. We envisioned that the consequences of this modification could be minimized if allylated phenol $\mathbf{5}$ were used as the monomer (Scheme 3). After formation of homodimer 6, a selective deallylation would reveal a free phenol (7) which would provide a handle for diversification, thereby recapturing some of the diversification potential at this position. We also hoped to utilize the remaining allyl group as a component of reactions designed to alter the scaffold structure of $\mathbf{7}$ and yield multiple new scaffolds.

The synthesis of resin-bound racemic homodimer is depicted in Scheme 4. Hydroquinone was monoallylated to yield $\mathbf{8}$, which was formylated under basic conditions to produce aldehyde 9. ${ }^{21}$ An $E$-selective Wittig reaction ${ }^{22}$ gave acid 10, which was reduced to alcohol 11 with lithium aluminum hydride. Direct resin loading of $\mathbf{1 1}$ gave a small amount of undesired attachment through the phenol hydroxyl, so the phenol was selectively protected as the acetate (12) prior to resin loading. ${ }^{23}$ Protodesilylation of the $\operatorname{resin}^{19}$ with triflic acid, addition of $\mathbf{1 2}$, and deprotection of the resulting resin-bound methyl ester with piperidine yielded the loaded resin 13 (loading level $=1.05 \mathrm{mmol} / \mathrm{g}$ resin).

Our attempts to prepare resin-bound homodimer 18 directly via $\mathrm{PhI}(\mathrm{OAc})_{2}$-mediated24 dimerization of silyl-protected $\mathbf{1 4}$ (step g) with $\mathbf{1 3}$ were not successful. The attempted dimerization proceeded cleanly; ${ }^{25}$ however, the mass recovery of cleaved homodimer $\mathbf{1 6}$ was only $50 \%$ based on the desired incorporation of one molecule of $\mathbf{1 4}$ per molecule of $\mathbf{1 3}$. The most likely explanation for this occurrence is that exclusive intra-bead homodimerization occurred producing cross-linked 15. Indeed, treatment of $\mathbf{1 3}$ with $\mathrm{PhI}(\mathrm{OAc}) 2$ in the absence of 14 gave a quantitative yield of homodimer 16 after resin cleavage, presumably via $\mathbf{1 5 .}$

Intra-bead homodimerization was unacceptable because it reduced the loading level of the resin by $50 \%$. To avoid this complication, we loaded onto the resin a mixture of molecules ${ }^{17 a}$ and 17b. ${ }^{17 a}$ and ${ }^{17 b}$ were prepared by a solution-phase homodimerization of $\mathbf{1 1}$ to produce $\mathbf{1 6}$ (step j) and subsequent monosilylation. Loading took place successfully to yield the corresponding 
mixture of resin-bound isomers $18 \mathbf{a}$ and $\mathbf{1 8 b} .{ }^{26}$ With resin-bound scaffold 18 in hand, we began to investigate reactions that would lead to a diverse library of molecules.

\section{On the Mechanism of Phl(OAc) $)_{2}$-Promoted Oxidative Dimerization}

The Chapman biomimetic synthesis of carpanone used stoichiometric $\mathrm{PdCl}_{2}$ as the oxidant to effect dimerization of $o$-hydroxystyrene 19 (Scheme 5(a)). ${ }^{11}$ According to Chapman's proposal, the initial step involves formation of bisphenoxy $\mathrm{Pd}(\mathrm{II})$ intermediate 20. Oxidation of $\mathbf{2 0}$ and concomitant reduction of $\mathrm{Pd}(\mathrm{II})$ to $\mathrm{Pd}(0)$ generates 21, which then undergoes an endo-selective, intramolecular, inverse-electron demand [4 + 2] cycloaddition affording carpanone. It was suggested that the dimerization of intermediate $\mathbf{2 0}$ may be radical-mediated, in which case the high diastereoselectivity observed in the formation of $\mathbf{2 1}$ is difficult to explain.

We found that $\mathrm{PhI}(\mathrm{OAc})_{2}$ is a superior reagent for this transformation based on our investigations with similar $o$-hydroxystyrenes in solution-phase and solid-phase syntheses (Scheme 4). We propose a different mechanism for the PhI-(OAc) $)_{2}$-mediated oxidative dimerization that accounts for the high diastereoselectivity and suggest that the reaction reported by Chapman with $\mathrm{PdCl}_{2}$ may proceed via similar intermediates (Scheme 5(b)). Our proposed mechanism involves activation of $\mathbf{1 9}$ by $\mathrm{PhI}(\mathrm{OAc}) 2$ to yield 22 followed by oxidative addition of a second molecule of $\mathbf{1 9}$ generating $\mathbf{2 3}$. This mechanism of oxidation of phenols is well-precedented. ${ }^{27}$ Intermediate $\mathbf{2 3}$ is now poised for an intramolecular, inverse-electron demand, endo-selective [4+2] cycloaddition to afford carpanone. A feature of this mechanism is that the observed diastereoselectivity is derived from the endo-selectivity of a cycloaddition rather than from a radical-mediated coupling.

\section{Solution-Phase Reaction Development}

Understanding that a library composed of molecules that each possess the same scaffold as 18 is less diverse than one with multiple scaffolds, we sought to increase the skeletal diversity of the library. ${ }^{20}$ Initial studies were performed on model system 29 in solution, which allowed convenient monitoring of reaction progress by thin-layer chromatography (Scheme 6).

Monomer 24, synthesized using chemistry analogous to that employed in the synthesis of $\mathbf{1 0}$ (see Supporting Information), was exposed to $\mathrm{PhI}(\mathrm{OAc}) 2$, yielding 25 . Enone 25 was selectively deallylated ${ }^{28}$ to yield phenol 26, which was then methylated to yield $\mathbf{2 7}$. Methyl ether $\mathbf{2 7}$ was then reduced diastereoselectively under Luche conditions ${ }^{29}$ to generate allylic alcohol 28, which was esterified to yield acrylic ester $\mathbf{2 9}$.

Ester 29 was processed along a branching pathway to produce two distinct scaffolds depending on which transition-metal-mediated reaction was employed (Scheme 7). Treatment of $\mathbf{2 9}$ with palladium acetate, silver carbonate, and triphenylphosphine initiated a rearrangement via a $\pi$ allyl palladium intermediate to yield 30, a molecule with one additional ring. ${ }^{30}$ Alternately, treatment with the second-generation Grubbs metathesis catalyst ${ }^{31}$ yielded 31, a molecule with two new rings formed at the expense of one ring from 29. Furthermore, treatment of $\mathbf{3 1}$ with acid resulted in an additional scaffold modification to yield furan phenol 32, a molecule that lacks two of the four rings originally present in 29. From a single precursor (29), three new scaffolds were created utilizing three different reactions. Unfortunately, despite considerable effort, all attempts to effect the Luche reduction of enone $\mathbf{1 8}$ in the solid phase failed, which effectively precluded application of these scaffold diversification reactions in the solid phase. Possible reasons for this failure include the deleterious effect that polar solvents have on the swelling properties of the hydrophobic polystyrene resin and ineffective diffusion of the metal or hydride source into the resin. Occasional difficulties with reagent diffusion through these macrobeads, especially with metallic reagents, have been noted. ${ }^{17 \mathrm{~b}}$ A screen of alternate reduction methods also failed. ${ }^{32}$ These results highlight the difficulties associated with translation of solution-phase chemistry to the solid phase. 
We had also sought to increase the skeletal diversity of the library by removing the allyl group of 29 and cleaving the resulting hemiketal to the corresponding ketone and phenol, two functional groups that could be further diversified. Although the allyl group could be removed by treatment with $\mathrm{Pd}\left(\mathrm{PPh}_{3}\right)_{4}$ and $\mathrm{PhSiH}_{3}$, the resulting hemiketal resisted cleavage under both acidic and basic conditions.

\section{Solid-Phase Reaction Development}

Given the difficulties associated with translating our solution-phase chemistry to the solid phase, we elected to perform all subsequent reaction development in the solid phase. Our attention first turned to diversity-generating reactions involving the enone of $\mathbf{1 8}$ (Scheme 8). Treatment of $\mathbf{1 8}$ with methylamine and $O$-ethylhydroxyl-amine resulted in the formation of oxime 33 as a mixture of oxime geometrical isomers (Path A). ${ }^{33}$ Such multicomponent reactions (MCRs) are advantageous as they incorporate building blocks more rapidly than the corresponding stepwise processes, and they minimize the potential for resin bead breakage by minimizing the number of reactions to which each resin bead is exposed. Other combinations of amines and hydroxylamines that participated in this MCR are presented in Chart 2. Building blocks were validated by performing each solid-phase test reaction on a scale sufficient to provide approximately $5 \mathrm{mg}$ of crude product following cleavage from the resin. An ${ }^{1} \mathrm{H}$ NMR of each crude product was then taken to provide a rough assessment of product purity, and only building blocks that gave $>90 \%$ yield of the desired product were incorporated into the library. 34

Primary amines were used exclusively in our conjugate additions since a MCR with a primary amine would generate a secondary amine that could be further functionalized. For example, addition of chloroformates to resin-bound $\mathbf{3 3}$ yielded carbamate products of which $\mathbf{3 4}$ is a representative example (Scheme 8). Furthermore, conversion of $\mathbf{3 3}$ to $p$-nitrophenyl-carbamate $\mathbf{3 5}$ allowed, after subsequent heating with a primary amine, access to ureas, such as $\mathbf{3 6}$ (Path B). ${ }^{35}$ Amides and sulfonamides were also produced by reaction of $\mathbf{3 3}$ with the corresponding acyl and sulfonyl chlorides (see Chart 2 and Supporting Information). During subsequent preparation of a small test library prior to synthesis of the full 10,000-membered library, we observed that the secondary amines bearing the largest substituents frequently did not undergo complete conversion to the corresponding sulfonamides and ureas, so these combinations of diversification reactions were excluded from the final library plan.

We then sought to extend this MCR to sulfur nucleophiles; however, treatment of $\mathbf{1 8}$ with aryl thiols in place of amines under the conditions developed for production of $\mathbf{3 3}$ led to highly variable results. ${ }^{36}$ This reaction was not general enough to be included in the library synthesis. However, the 1,4-addition of aryl thiols to enones was successfully accomplished in a previous library, ${ }^{10}$ so we attempted to apply this reaction to our system. Treatment of $\mathbf{1 8}$ with benzenethiol under basic conditions cleanly produced thioether 37 (Path C). In a second step, oxime 38 was successfully prepared using an adaptation of the conditions developed for the synthesis of 33. Every hydroxylamine that proved successful for oxime formation in the amine MCR was also successful in the thiol series. Aliphatic thiols could be incorporated if $n$-BuLi and 2,6-lutidine were used in place of triethylamine. Successful thiol building blocks are presented in Chart 2.

Azides have been described as one of the functional groups that reliably participates in a number of solution-phase organic reactions. ${ }^{37} \mathrm{We}$ sought to incorporate the azide functional group into our library in hopes that its well-established solution-phase reactivities would prove equally reliable in our solid-phase synthesis. Given the success of using primary amines as nucleophiles in a MCR with enone $\mathbf{1 8}$ (Path A), we investigated whether azide anion could also act as a nucleophile in the MCR in hopes of taking advantage of, in subsequent steps, the reactivity of azides toward alkynes. ${ }^{38}$ The desired MCR was successfully achieved (Scheme 8, Path D) to 
give azide 39. Every hydroxylamine that proved successful for oxime formation in the amine MCR was also successful in the azide MCR. We were then pleased to discover that the thermal cycloaddition reaction of azide 39 with dimethylacetylene dicarboxylate yielded triazole $\mathbf{4 0}$ and that the copper-catalyzed cycloaddition reaction of $\mathbf{3 9}$ with phenylacetylene yielded $\mathbf{4 1}$.

${ }^{39}$ Successful acetylene building blocks are presented in Chart 2.

With the enone functional group now sufficiently diversified, the phenol allyl group was selectively cleaved in the presence of the ketal allyl group using $\mathrm{Pd}\left(\mathrm{PPh}_{3}\right)_{4}$ and $\mathrm{PhSiH}_{3}$. Representative examples of this reaction are presented in Scheme 9. With careful control of reaction time, a selective deprotection could be achieved for all library members except those containing urea and triazole substructures. In molecules containing these two substructures, the ketal allyl group was partially removed as well and could be completely removed after an extended reaction time. ${ }^{40}$ To avoid potential complications arising from having two free alcohols present within any library compound, final library members containing urea and triazole substructures were segregated following global deallylation and were not further diversified.

Reaction development on the free phenols produced from the selective deprotection reactions was complicated by the growing size of the potential library. Using all combinations of reactions and building blocks discussed to this point, over 700 unique compounds could be generated in a split-and-pool synthesis. Clearly, further reaction development and building block testing could be performed efficiently on only a small subset of these 700 compounds. The inability to optimize late-stage reactions for all members of a split-and-pool synthesis is one drawback of this synthesis technique. Nonetheless, we felt that careful optimization of reaction conditions and building blocks for a small subset of potential library compounds would produce reactions that could be extended to all library members. Combined phenols $\mathbf{4 4}$ were diversified using three distinct reactions: (1) copper-catalyzed biaryl coupling with phenols $\left(\mathbf{4 4} \rightarrow \mathbf{4 5}\right.$, Path A, Scheme 10) ${ }^{41}$ (2) Mitsunobu substitution with aliphatic alcohols (44 $\rightarrow$ $\mathbf{4 6}$, Path B), ${ }^{42}$ and (3) carbamate formation with isocyanates $(\mathbf{4 4} \rightarrow \mathbf{4 7}$, Path C). The building blocks that were successfully employed in these reactions are presented in Chart 2.

\section{Split-and-Pool Library Synthesis}

Utilizing the above diversity-generating reactions and building blocks, a final library of 10,102 molecules was prepared via split-and-pool synthesis using a "one bead-one stock solution" strategy. ${ }^{17}$ The library was prepared in triplicate, using approximately 30,000 macrobeads (polystyrene, $500 \mu \mathrm{m}, 100 \mathrm{nmol}$ per bead capacity) at the outset to account for such factors as occasional bead breakage, removal of a small quantity of beads after each step for quality control analysis, and the inherent inability of the split-and-pool method to synthesize $100 \%$ of the theoretical number of compounds. ${ }^{43}$ After each step, a fraction of the resin was reserved so that each intermediate in the synthesis would be represented in the final library of compounds. To facilitate structure determination of library compounds, we used an adaptation of the encoding strategy developed by Still. This strategy involves Rh(II)-catalyzed carbene insertion of diazoketones bearing unique combinations of halogenated aryl groups ("tags") into the polystyrene resin following each reaction. ${ }^{44}$ These tags are oxidatively removed from each resin bead after compound release and are analyzed by GC. The peaks in the GC trace indicate the specific tags used to encode the bead's reaction history, thus revealing the identity of the compound attached to that bead.

The initial quantity of scaffold-loaded resin (18) was split into three portions. One portion was divided into 36 batches. Each batch was tagged with a unique combination of tags and was treated with one of 36 combinations of six amines and six hydroxylamines to yield 36 compounds (Scheme 11, Path A). Rigorous quality control was performed on all 36 batches. A small amount of each compound was cleaved (HF. pyridine) and analyzed by LC-MS. All 
36 batches showed $>90 \%$ purity, and the GC trace from each bead showed all expected peaks corresponding to the proper tag combinations for each reaction. These compounds were pooled, and a portion was removed for inclusion in the final library. The remainder was split into batches and tagged prior to treatment with one of 19 acid chlorides, sulfonyl chlorides, and chloroformates (Paths B and C). The 24 compounds bearing large amine groups at the $\mathrm{R}^{1}$ position were found to be incompatible with the larger members of the chloroformate, acid chloride, and sulfonyl chloride families of building blocks, so these compounds were reacted with a subset of these building blocks bearing smaller $\mathrm{R}^{3}$ groups (Path B, see Supporting Information for full details). The 12 compounds bearing small amine groups at the $\mathrm{R}^{1}$ position were reacted with all 19 building blocks (Path C). A subset of 12 of these products bearing a $p$-nitrophenyl chloroformate moiety was further converted into ureas through treatment with one of five primary amines (Path D). An additional 576 compounds were produced overall in this sequence (Paths B, C, and D). GC analysis on a sample from each batch of resin confirmed the presence of proper tag combinations.

A second portion of the initial quantity of scaffold-loaded resin (18) was split into nine batches and tagged, and each batch was treated with one of nine thiols (Scheme 12, Path E). Quality control on each batch indicated that one of the nine products was not generated with $>90 \%$ purity, so this batch was removed from the library. The remaining batches were pooled, a portion was removed for inclusion in the final library, and the remainder was split into seven new batches and tagged. Six batches were treated with one of six hydroxylamines to yield 48 oximes (Path F). The seventh batch was left unreacted to ensure the presence of ketones in the final library. GC analysis on a sample from each batch of resin confirmed the presence of proper tag combinations.

A third portion of the initial quantity of scaffold-loaded resin (18) was split into six batches and tagged, and each batch was treated with trimethylsilyl azide and one of six hydroxylamines (Scheme 13, Path G). Quality control analyses indicated that all six products were formed with $>90 \%$ purity and confirmed the presence of proper tag combinations. The six batches were pooled, split into 13 new batches, tagged, and treated with one of 13 alkynes (Path H). Again, $\mathrm{GC}$ analysis on a sample from each batch of beads confirmed the presence of proper tag combinations. A total of 716 unique compounds had been produced at this stage (Paths A-H).

At this stage, all batches of beads, with the exception of batches bearing urea and triazole substructures, were pooled (Scheme 14). A small portion was removed to ensure the presence of bisallylated structures in the final library. The remainder was tagged and subjected to deallylation conditions (Path I). A small portion was then removed to ensure the presence of free phenols in the final library. The remaining resin was split into 15 batches and reacted with one of 15 alcohols, aryl boronic acids, and isocyanates (Path J). In lieu of tagging, these batches were not pooled at the end of the synthesis. Each batch was arrayed separately during library formatting, which allowed the identity of the final reaction performed on individual beads to be deduced from the location of the bead in the array. ${ }^{45}$

\section{Library Formatting and Quality Control}

The 30,000 individual macrobeads were then arrayed into 384-well microtiter plates such that only one bead was present in each well. The plates were subjected to an automated cleavage process ${ }^{17}$ in which each well was treated with $20 \mu \mathrm{L}$ of an HF.pyridine solution $(5 \% \mathrm{HF}$. pyridine, $5 \%$ pyridine in THF) to remove the compound from the resin followed by treatment with $20 \mu \mathrm{L}$ of methoxytrimethylsilane to quench any excess HF. After evaporation of volatiles, the beads were washed with three successive $30 \mu \mathrm{L}$ portions of DMF, and the combined eluates were transferred into fresh 384-well plates. The stock solutions contained in these "mother plates" were transferred to multiple sets of "daughter plates" for use in cell-based assays, 
compound archives, and quality control analyses. The encoding tags on the beads were then oxidatively cleaved and subjected to GC analysis for structure identification.

Quality control was performed on the final library by analyzing three randomly selected compound solutions from each of the forty-eight 384-well daughter plates containing the final library members. In all, 146 compound solutions were analyzed by LC-MS, which accounts for approximately $1.5 \%$ of the total number of compounds in the library. The results of these analyses are detailed in the Supporting Information and are summarized here; $84 \%$ of the compounds were successfully identified by matching the structure inferred from GC tag decoding to the mass spectrum of the major peak in the LC; $12 \%$ of the compounds analyzed had a structure that could be deduced from GC tag decoding but that could not be correlated to the major peak in the LC-MS; $4 \%$ of the compounds analyzed had structures that could not be deduced from GC tag decoding.

\section{Cell-Based Phenotypic Screen}

The secretory pathway involves the transport of properly folded proteins from the endoplasmic reticulum (ER) through the Golgi apparatus to the plasma membrane. The study of individual components of this pathway would be aided if specific small-molecule regulators of each of its many steps were available. A number of small molecules have been shown to affect the secretory pathway. For example, the natural product brefeldin A specifically and reversibly blocks protein transport out of the ER and causes tubulation of the Golgi membranes via inhibition of the GTPase Arf1. ${ }^{46}$ Secramine, a molecule derived from a recent DOS library prepared in our laboratory, ${ }^{10}$ blocks protein transport from the Golgi apparatus to the plasma membrane, an effect complementary to that of brefeldin A. ${ }^{2}$ Other molecules, such as norrisolide,${ }^{47}$ nocodazole,${ }^{48}$ and illimaquinone, ${ }^{49}$ have been shown to induce fragmentation of the Golgi apparatus. Each of these molecules has proven useful in studying vesicular traffic since vesicular traffic is a rapid process that is best perturbed by fast-acting small molecules.

Through a combination of diversity-oriented synthesis and high-throughput phenotypic screens, our laboratory intends to discover additional small molecules that perturb the proper function of the secretory pathway in order to provide additional tools for probing this pathway. Utilizing an image-based phenotypic screen that we developed previously, ${ }^{50}$ we screened the carpanone-based library for molecules that perturb exocytic traffic of membrane proteins from the ER to the plasma membrane. The screen utilizes the temperature-sensitive vesicular stomatitis virus glycoprotein fused to green fluorescent protein (VSVG $\left.{ }^{\text {ts }}-\mathrm{GFP}\right)$. At the nonpermissive temperature of $40^{\circ} \mathrm{C}, \mathrm{VSVG}^{\text {ts }}-\mathrm{GFP}$ accumulates in the ER. On cooling to 32 ${ }^{\circ} \mathrm{C}$, VSVG ${ }^{\text {ts }}$-GFP synchronously passes from the ER to the plasma membrane via the Golgi apparatus. ${ }^{51} \mathrm{We}$ screened 8,685 members of the carpanone library in duplicate at $\sim 22 \mu \mathrm{M}$. Each compound was added to BSC1 cells (monkey kidney epithelial cells) expressing $\mathrm{VSVG}^{\text {ts }}$-GFP at $40^{\circ} \mathrm{C}$ in 384 -well plates. After 1 hour, the cells were shifted to $32^{\circ} \mathrm{C}$ for 3 hours, fixed, and imaged using an automated fluorescence microscope. Thirteen compounds were visually identified for perturbing the intracellular distribution of VSVG ${ }^{\text {ts }}$ GFP. The inhibitory activity of these compounds could be characterized by two distinct phenotypes (Figure 1A): (1) Golgi exit block, and (2) Golgi fragmentation. The remaining compounds either had no effect on trafficking or showed toxic effects exemplified by cell rounding and/ or reduced cell count. In this report, we focus on the class of compounds that blocks VSVG ${ }^{\text {ts }}$ GFP exit from the Golgi (Figure 1B).

We selected the most potent inhibitors from this class ("hits") for resynthesis and further investigation. In addition to preparing a large quantity (approximately $10 \mathrm{mg}$ ) of each hit via solid-phase synthesis, we prepared samples of intermediates along each synthesis pathway so that preliminary structure-activity relationships could be established. Following cleavage from 
the resin, each sample was purified using standard flash chromatography prior to biological evaluation.

All members of this class have a secondary amine or carbamate at $\mathrm{R}^{2}$ and an oxime at $\mathrm{R}^{1}$ (Figure 1C). CLL-19 is the most potent and displays an $\mathrm{IC}_{50}$ of $\sim 14 \mu \mathrm{M}$. In general, substitution of an $o$-fluorobenzyl group for an allyloxy or hydroxyl group at $\mathrm{R}^{3}$ led to a decrease in inhibitory activity (Figure 1E). Furthermore, replacement of the secondary amine at $\mathrm{R}^{2}$ with an ethyl carbamate reduced the inhibitory activity among all members of this class (compare CLL-23 to CLL-19, and Figure 1E). Benzyloxyethyl carbamate substitution further compromised the inhibitory activity compared to the secondary amine (Figure 1F). Interestingly, carpanone did not perturb VSVG ${ }^{\text {ts }}$-GFP trafficking at $300 \mu \mathrm{M}$. Furthermore, the library core (16) did not affect trafficking and is severely toxic to cells at concentrations $>33 \mu \mathrm{M}$ (Figure 1C).

We chose to further investigate CLL-19, which inhibits exocytosis by blocking exit of $\mathrm{VSVG}^{\text {ts }}-\mathrm{GFP}$ from the Golgi with an $\mathrm{IC}_{50}$ of $\sim 14 \mu \mathrm{M}$. To investigate its specificity for membrane traffic inhibition, we tested the effect of CLL-19 on other cellular properties. CLL-19 did not inhibit the uptake of fluorescently labeled cholera toxin from the cell surface to perinuclear regions (Figure 2A). It also did not inhibit the uptake of the fluorescently labeled endocytic receptor ligand transferrin from the plasma membrane to endosomes; however, it did alter the intracellular distribution of the perinuclear transferrin-containing endosomes (Figure 2A). Moreover, CLL-19 did not affect the cellular cytoskeleton as evidenced by the integrity of both actin and tubulin networks following treatment with CLL-19. Thus, CLL-19 did not induce general defects in clathrin-dependent and clathrin-independent intracellular membrane trafficking or in the organization of the cellular cytoskeleton and is, therefore, a specific inhibitor of VSVG ${ }^{\text {ts }}$-GFP trafficking.

To further characterize the activity of CLL-19, and to better understand its inhibitory effects on vesicular traffic, we examined whether CLL-19 altered the steady-state distribution of a series of different intracellular organelle markers along the exocytic and endocytic pathways (Figure 2B). Three hour treatment of BSC1 cells with $33 \mu \mathrm{M}$ CLL-19 did not affect the distribution of the sec13p marker specific for the ER exit sites. CLL-19 also did not affect the localization of the Golgi matrix protein GM130 (Figure 2B), suggesting that the integrity of the Golgi apparatus is maintained. The KDEL receptor (KDELr), which recycles between the Golgi and ER, appeared slightly more condensed upon treatment with CLL-19, while the perinuclear signal of the coat protein clathrin was normal. These results suggest that the Golgi apparatus remains intact upon treatment with CLL-19, although VSVG ${ }^{\text {ts }}$-GFP export from the Golgi is abrogated.

We next investigated the effect of CLL-19 on cell cycle progression. We incubated CLL-19 with BSC-1 cells, followed by fixing and staining for DNA and phosphoHistone 3 antibody (a marker for cells in the mitosis phase). After a 6 hour treatment, we found that the mitotic index, measured by percentage of cells in mitosis, decreased from 7.3 to $0.8 \%$ on treatment with 33 $\mu \mathrm{M}$ CLL-19 (Figure 3A). As expected, the anti-mitotic control compound nocodazole increased the mitotic index to $16.7 \%$ (i.e., more cells were present in mitosis), indicating that cells were not able to exit the mitotic phase. The results of cell cycle analysis by flow cytometry allowed a better understanding of drug effects on cell cycle progression. CLL-19-treated cell cultures $(33 \mu \mathrm{M}$ ) became enriched in S phase (up 12.2\%) after 6 hours. CLL-19-treated cell cultures also showed a decrease in number of cells in the G2/M phase, in agreement with the mitotic index assays. These results strongly suggest that CLL-19 has an effect on growth that may be linked to partial blockage of dividing cells in $\mathrm{S}$ phase, hence slowing their rate of entry into mitosis (Figure 3B; see drop in number of cells in the G2/M phase). Further detailed investigations into the biology of CLL-19 and other hits from the carpanone library with distinct phenotypes are ongoing and will be reported in due course. 


\section{Conclusions}

A 10,000-membered library of carpanone-like molecules has been prepared in a split-and-pool solid-phase synthesis that relied on adaptations of well-established solution-phase methodologies, application of known solid-phase methodologies, and development of a key multicomponent reaction between nitrogen nucleophiles, enones, and hydroxylamines. A phenotypic screen of the library has identified compounds that perturb the secretory pathway by inhibiting the exit of proteins from the Golgi apparatus. This study further underscores how libraries based upon natural products combined with phenotypic screens can be useful in identifying molecules with new functions.

\section{Acknowledgments}

Financial support from an NSF CAREER award to M.D.S. and from NIH (P01 GM62566-05) to T.K. is acknowledged. In support of the ICCB, grants from the NCI, Merck Research Labs, and Merck KgaA are acknowledged. B.G. acknowledges an NDSEG graduate research fellowship. R.H. acknowledges an NSERC postdoctoral research fellowship. We thank John Tallarico, Jennifer Raggio, and Leticia Castro for expert supervision of library formatting and quality control; Ramiro Massol, Werner Boll, and Yan Feng for experimental assistance and thoughtful discussions; and Yoshiki Tanaka for resynthesis of two key compounds.

\section{References}

1. Mita MM, Mita A, Rowinsky EK. Cancer Biol Ther 2003;2:S169-S177. [PubMed: 14508096]

2. Klausner RD, Donaldson JG, Lippincott-Schwartz J. J Cell Biol 1992;116:1071-1080. [PubMed: 1740466]

3. Pathak AN, Srivastava A. J Sci Ind Res India 1998;57:862-872.

4. Shigemori H, Kobayashi J. J Nat Prod 2004;67:245-256. [PubMed: 14987066]

5. Alberts AW. Am J Cardiol 1988;62:10J-15J.

6. (a) Webb TR. Curr Opin Drug Discovery 2005;8:303-308. (b) Spring DR. Org Biomol Chem 2003;1:3867-3870. [PubMed: 14664374] (c) Schreiber SL. Science 2000;287:1964-1969. [PubMed: 10720315]

7. (a) Piggott AM, Karuso P. Comb Chem High Throughput Screening 2004;7:607-630.(b) For an alternative theory on why nature produces diverse natural products, see: FirnRDJonesCGNat Prod Rep200320382391 [PubMed: 12964834]

8. For a review on the integration of natural products in library synthesis, see: PaululatTTangYQGrableySThierickeRChim Oggi1999175256and references therein.

9. de la Torre MC, Sierra MA. Angew Chem, Int Ed 2003;43:160-181.

10. Pelish HE, Westwood NJ, Feng Y, Kirchhausen T, Shair MD. J Am Chem Soc 2001;123:6740-6741. [PubMed: 11439080]

11. Chapman OL, Engel MR, Springer JP, Clardy JC. J Am Chem Soc 1971;93:6696-6698.

12. For a solid-phase synthesis of carpanone itself which appeared after our initial report, ${ }^{15}$ see: BaxendaleIRLeeALLeySVJ Chem Soc, Perkin Trans 1200218501857

13. Though technically a dienone, one of the dienone olefins in the scaffold is not in conjugation with the carbonyl, rendering it unreactive as a conjugate acceptor (vide infra).

14. nOe experiments on the conjugate addition adduct of thiophenol and a representative library core synthesized in our previous communication ${ }^{15}$ confirmed that conjugate addition occurs diastereoselectively from the convex face of the enone.

15. Lindsley CW, Chan LK, Goess BC, Joseph R, Shair MD. J Am Chem Soc 2000;122:422-423.

16. Institute for Chemistry and Cell Biology, Harvard University, Cambridge, MA.

17. The standard resin used by the ICCB is a derivative of $500 \mu \mathrm{m}$ polystyrene resin with a diisopropylp-methoxyphenylsilyl terminus. See: (a) Sternson SM, Louca JB, Wong JC, Schreiber SL. J Am Chem Soc 2001;123:1740-1747. [PubMed: 11456775] (b) Spring DR, Krishnan S, Blackwell HE, Schreiber SL. J Am Chem Soc 2002;124:1354-1363. [PubMed: 11841305] (c) Blackwell HE, Pérez 
L, Stavenger RA, Tallarico JA, Eatough EC, Foley MA, Schreiber SL. Chem Biol 2001;8:11671182. [PubMed: 11755396](d)

18. For an analysis of site-site interactions, see: HodgePChem Soc Rev199726417424

19. Tallarico JA, Depew KM, Pelish HE, Westwood NJ, Lindsley CW, Shair MD, Schreiber SL, Foley MA. J Comb Chem 2001;3:312-318. [PubMed: 11350255]

20. Burke MD, Schreiber SL. Angew Chem, Int Ed 2004;43:46-58.

21. Baker R, Castro JL. J Chem Soc, Perkin Trans 1 1990:47-65.

22. Suzuki Y, Takahashi H. Chem Pharm Bull 1983;31:1751-1753.

23. Torrini I, Zecchini GP, Agrosi F, Paradisi MP. J Heterocycl Chem 1986;23:1459-1463.

24. For a discussion of the reactivity of hypervalent iodine reagents, see: Varvoglis, A. Hypervalent Iodine in Organic Synthesis; Elsevier: London, 1996.

25. As judged by the crude ${ }^{1} \mathrm{H}$ NMR of product 16, which was cleaved from the resin with HF.pyridine.

26. As deduced by ${ }^{1} \mathrm{H}$ NMR and mass recovery of 16 , obtained by HF.pyridine-mediated cleavage of $18 \mathrm{a}$ and $18 \mathrm{~b}$ from the resin. All subsequent studies showed that the mixture of $18 \mathrm{a}$ and $18 \mathrm{~b}$ behaved as if it were one isomer. Furthermore, the distinction between $18 \mathrm{a}$ and $18 \mathrm{~b}$ is transient. Following cleavage from the resin, both $18 \mathrm{a}$ and $18 \mathrm{~b}$ yield the same product (16).

27. (a) Zhdankin VV, Stang PJ. Chem Rev 2002;102:2523-2584. [PubMed: 12105935](b)See ref 24.

28. Jeffrey PD, McCombie SW. J Org Chem 1982;47:587-590.

29. Luche JL, Rodriguez-Hahn L, Crabbe P. J Chem Soc, Chem Commun 1978:601-602.

30. Oppolzer W. Angew Chem, Int Ed Engl 1989;28:38-52.

31. Grubbs RH. Tetrahedron 2004;60:7117-7140.

32. L-selectride, K-selectride, LAH, DIBAL-H, 9-BBN, and BH3 each led to a complex mixture of products including products of over-reduction and allyl group cleavage.

33. A mixture of oxime geometrical isomers was generally observed, in most cases with a ratio $>4: 1$, presumably in favor of the E isomer where the oxime substituent is oriented away from the carpanone core.

34. The crude ${ }^{1} \mathrm{H}$ NMR spectra for all numbered compounds produced in the solid phase are included in the Supporting Information.

35. Hutchins SM, Chapman KT. Tetrahedron Lett 1995;36:2583-2586.

36. Depending on the thiol, the outcomes included no reaction, 1,4-thiol incorporation only, oxime formation only, and the desired MCR. The results could not be correlated with the structure of the thiol.

37. Kolb HC, Finn MG, Sharpless KB. Angew Chem, Int Ed 2001;40:2004-2021.

38. (a) Rostovtsev VV, Green LG, Fokin VV, Sharpless KB. Angew Chem, Int Ed 2002;41:2596-2599. (b) Breinbauer R, Kohn M. ChemBioChem 2003;4:1147-1149. [PubMed: 14613105]

39. Himo F, Lovell T, Hilgraf R, Rostovtsev VV, Noodleman L, Sharpless KB, Fokin VV. J Am Chem Soc 2005;127:210-216. [PubMed: 15631470]See for recent insights into the mechanism of this copper-mediated reaction

40. We speculate that the increased coordinating capability of highly nitrogenated triazoles and ureas might deliver palladium to the allyl group nearest these functional groups, thus promoting undesired cleavage of the ketal allyl group.

41. For general reviews, see: (a)Whiting, D. A. Oxidative Coupling of Phenols and Phenol Ethers. In Comprehensive Organic Synthesis; Trost, B. M., Fleming, I., Pattenden, G., Eds.; Pergamon: Oxford, 1991; Vol. 3, pp 659-703. (b) Quideau S, Feldman KS. Tetrahedron 2001;57entire issue

42. Mitsunobu O. Synthesis 1981;1:1-28.

43. Due to the statistical improbability of splitting any mixture of solid-phase resin beads into identical heterogeneous batches, a certain percentage of the theoretical number of compounds in any splitand-pool library will not be made. This percentage is minimized when multiple copies of the library are prepared. Three copies of the carpanone library were prepared.

44. (a) Nestler HP, Bartlett PA, Still WC. J Org Chem 1994;59:4723-4724.(b)See ref 17c.

45. This process is known as position encoding. 
46. (a) Fujiwara T, Oda K, Yokota S, Takatsuki A, Ikehara Y. J Biol Chem 1988;263:18545-18552. [PubMed: 3192548](b)See ref 2.

47. Brady TP, Wallace EK, Kim SH, Guizzunti G, Malhotra V, Theodorakis EA. Bioorg Med Chem Lett 2004;14:5035-5039. [PubMed: 15380194]

48. Rogalski AA, Bergman JE, Singer SJ. J Cell Biol 1984;99:1101-1109. [PubMed: 6088553]

49. Takizawa PA, Yucel JK, Veit B, Faulkner DJ, Deernick T, Soto G, Ellisman M, Malhotra V. Cell 1993;73:1079-1090. [PubMed: 8513494]

50. Feng Y, Yu S, Lasell TKR, Jadhav AP, Macia E, Chardin P, Melancon P, Roth M, Mitchison T, Kirchhausen T. Proc Natl Acad Sci USA 2003;100:6469-6474. [PubMed: 12738886]

51. a Presley JF, Cole NB, Schroer TA, Hirschberg K, Zaal KJM, Lippincott-Schwartz J. Nature 1997;389:81-85. [PubMed: 9288971] b Scales SJ, Pepperkok R, Kreis TE. Cell 1997;90:1137-1148. [PubMed: 9323141] 
A

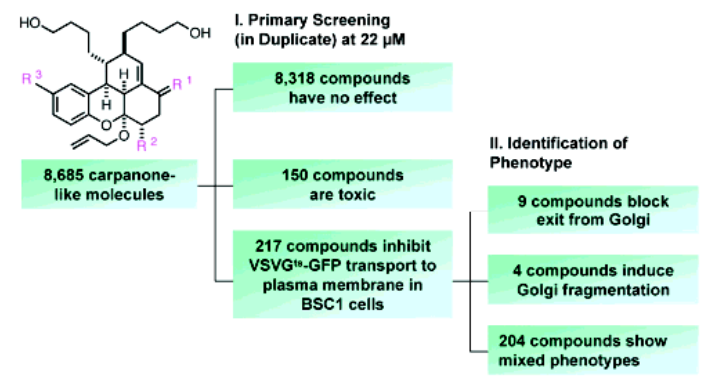

B

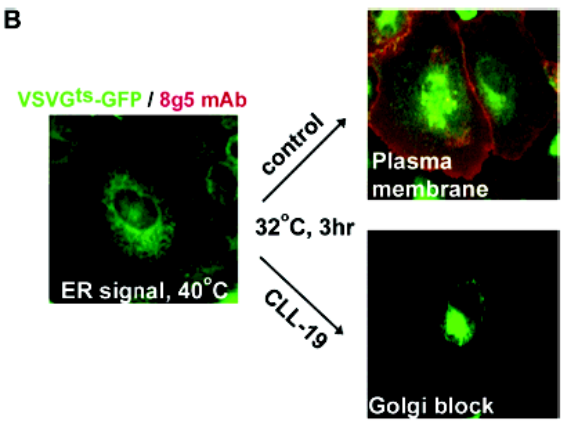

D

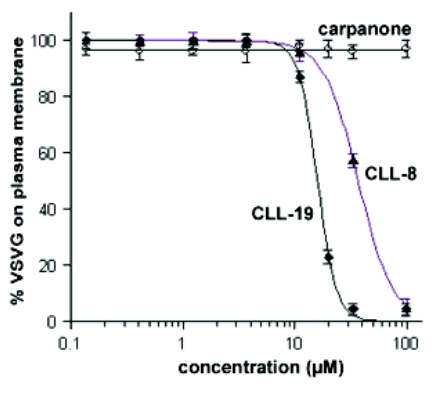

C
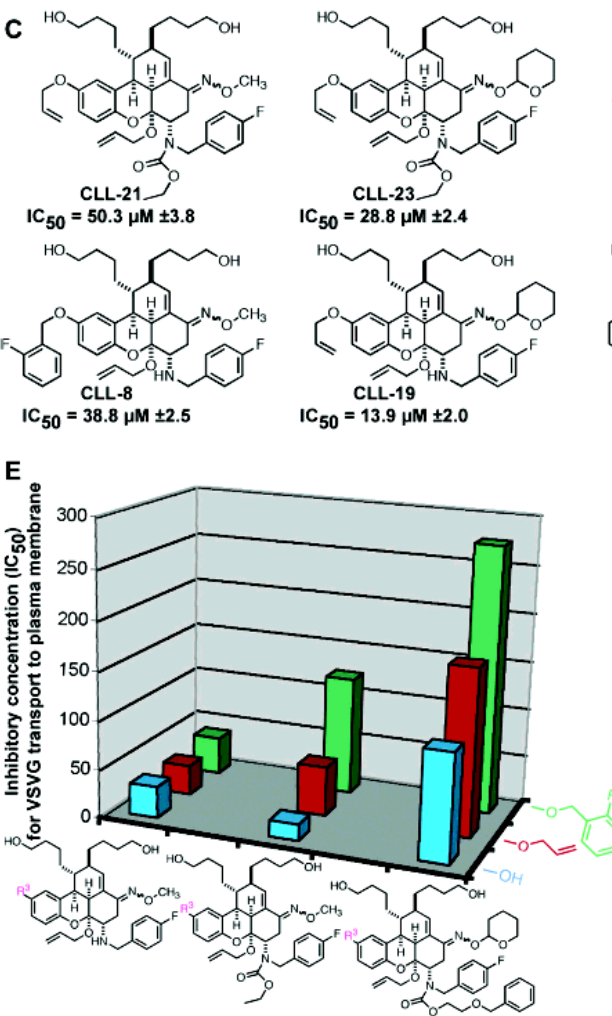

$\mathrm{IC}_{50}=13.9 \mu \mathrm{MM} \pm 2.0$

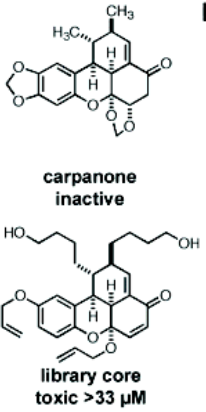

$\mathbf{F}$

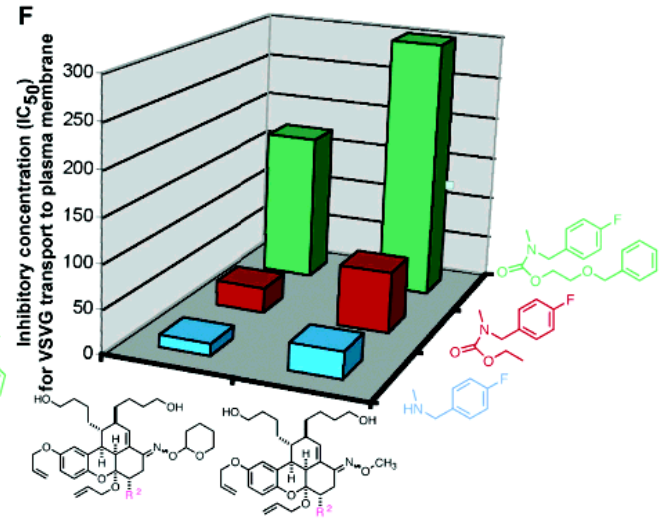

Figure 1.

High-throughput screening of a library of molecules resembling carpanone for inhibitors of VSVG $^{\text {ts }}$-GFP traffic. (A) Statistics of the hits that scored in the original screen: nine compounds were identified that block VSVG ${ }^{\text {ts }}$-GFP exit from the Golgi, and four compounds were identified that cause Golgi fragmentation. Also, many compounds exhibited nonspecific phenotypes that were mixtures of ER block and Golgi block. (B) Schematic illustrating the phenotype for the class of compounds that inhibits VSVG ${ }^{\mathrm{ts}}$-GFP exit from the Golgi. (C) Representative examples of the hits from the original screen and their derivatives that were resynthesized. (D) Representative dose response profiles for two of the most potent hits from the library. Also shown is the inactive carpanone natural product. (E) Structure-activity relationships (SAR) for the various hits at $\mathrm{R}^{3}$. Variations in this series did not significantly perturb the potency of the compounds, with the hydroxy and allyloxy groups showing the highest potencies compared to that of the o-fluorobenzyloxy group. (F) SAR of hits varying at position $\mathrm{R}^{2}$. In this series, potency decreases when the secondary amine is replaced with an ethyl carbamate or a benzyloxy ethyl carbamate. The methyl oxime was least potent regardless of the identity of the $\mathrm{R}^{2}$ group. 
A

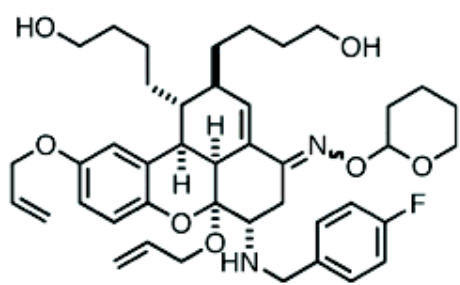

Control
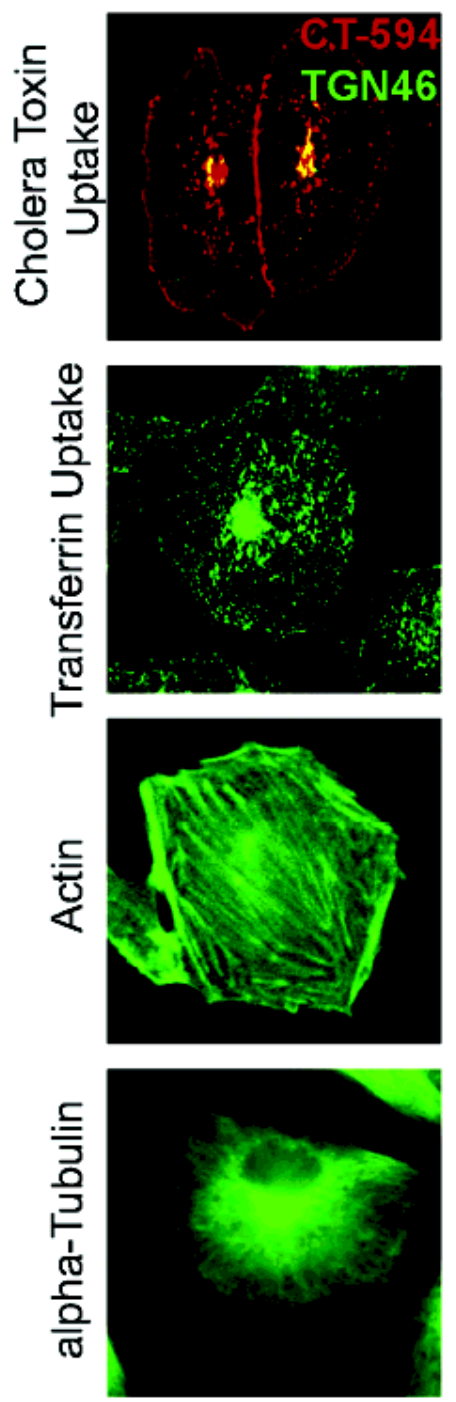

B
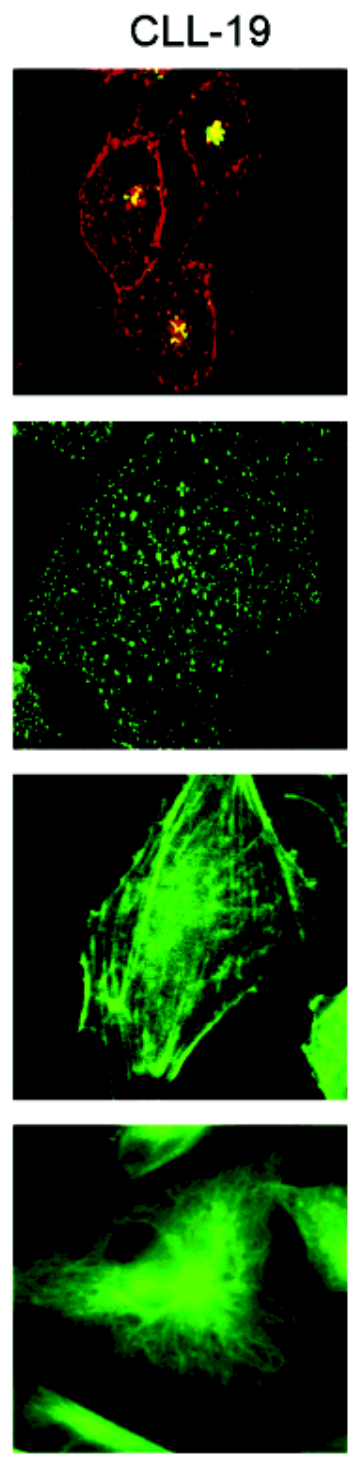<smiles></smiles>

1\% DMSO

Control

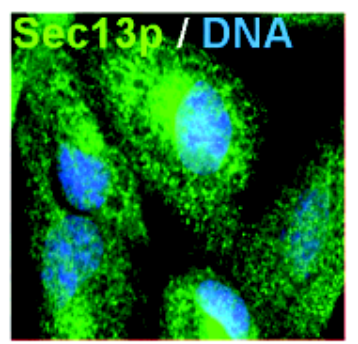

CLL-19
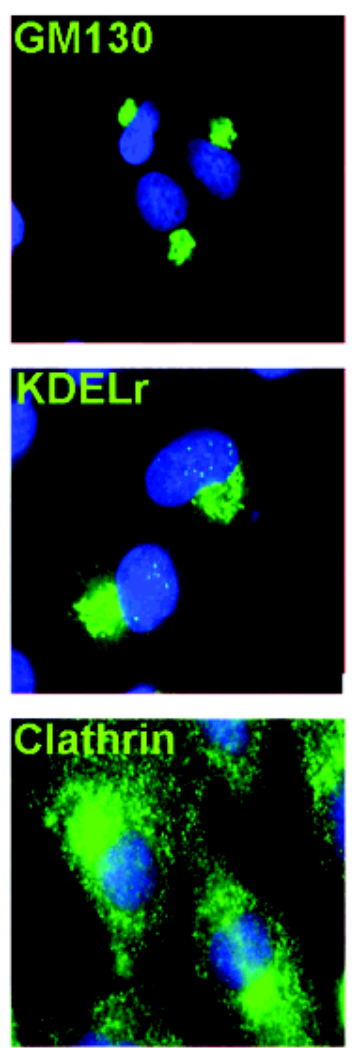
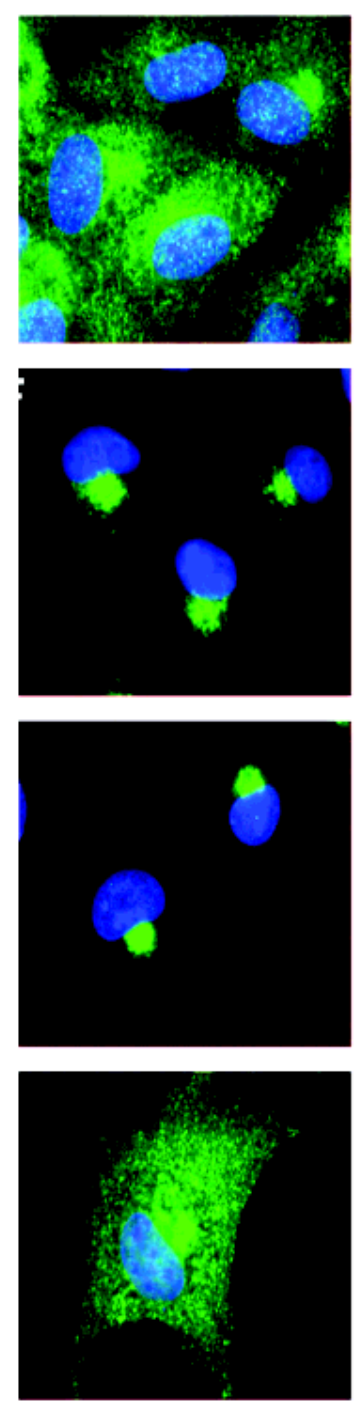

Figure 2.

Hit CLL-19, identified from a screen of a library of molecules resembling carpanone, is a specific inhibitor of VSVG ${ }^{\text {ts }}$-GFP traffic. (A) Endocytosis experiments illustrating that CLL-19 $(33 \mu \mathrm{M})$ does not have an effect on the uptake of fluorescently labeled cholera toxin (CT-594) or transferrin. Also shown are immunofluorescence experiments demonstrating that CLL-19 has no effect on the steady-state dynamics of actin or tubulin. (B) Immunofluorescence experiments probing the effect of CLL-19 on various cellular organelles. Three-hour treatment of $33 \mu \mathrm{M}$ CLL-19 does not affect the intracellular distribution of the ER exit sites marker sec13p, and the cis-Golgi marker GM130, suggesting that the architectural integrity of the Golgi is maintained. The KDEL receptor, which recycles between the ER and the Golgi, 
appears slightly condensed on treatment with CLL-19 compared to the control, while clathrin distribution appears normal. 

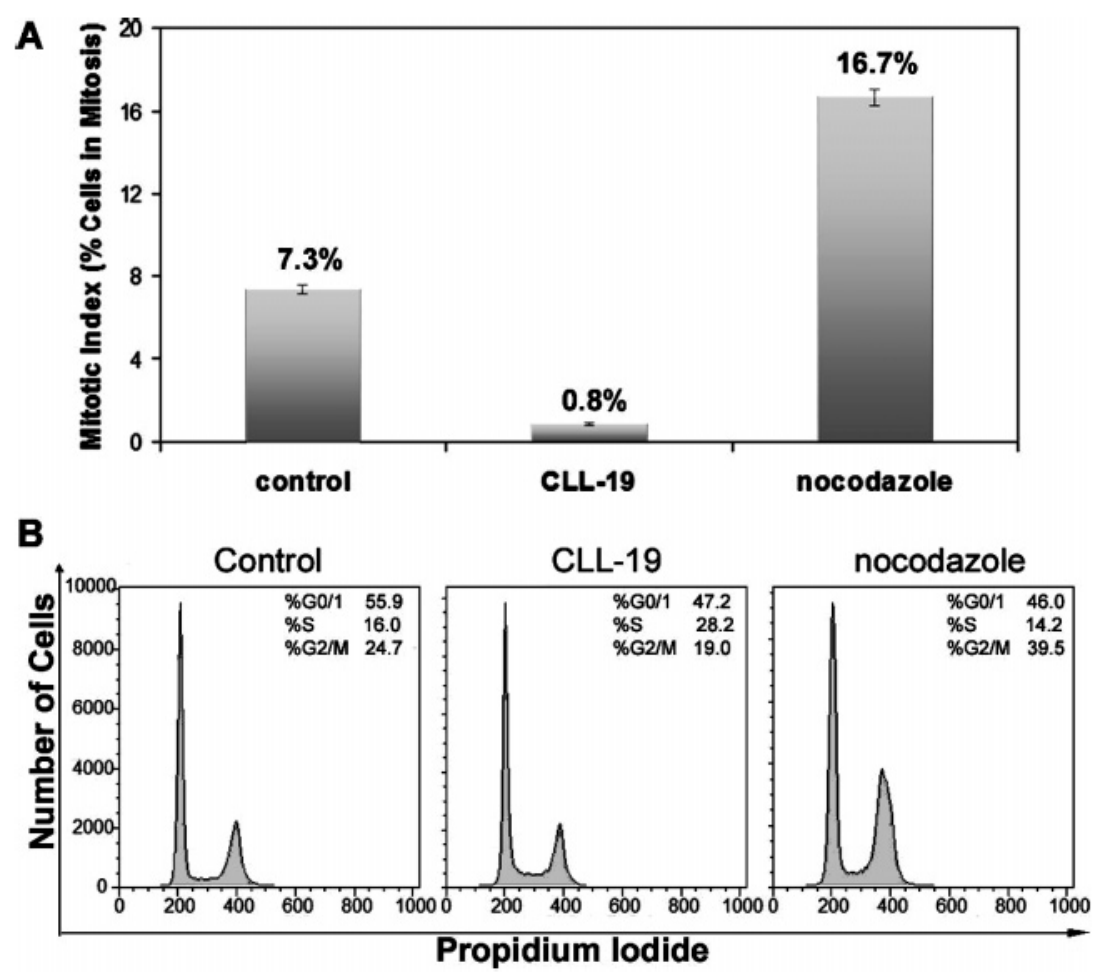

Figure 3.

Effect of CLL-19 on cellular division and cell cycle progression. (A) Mitotic index experiments measuring the percent of cells in mitosis after $6 \mathrm{~h}$ treatment with $33 \mu \mathrm{M}$ CLL-19 or $33 \mu \mathrm{M}$ nocodazole. (B) Flow cytometry experiments showing the decrease in the percent of cells in the $\mathrm{G} 2 / \mathrm{M}$ phase and their increase in the $\mathrm{S}$ phase following $6 \mathrm{~h}$ treatment with CLL-19. Nocodazole is shown as a control. 


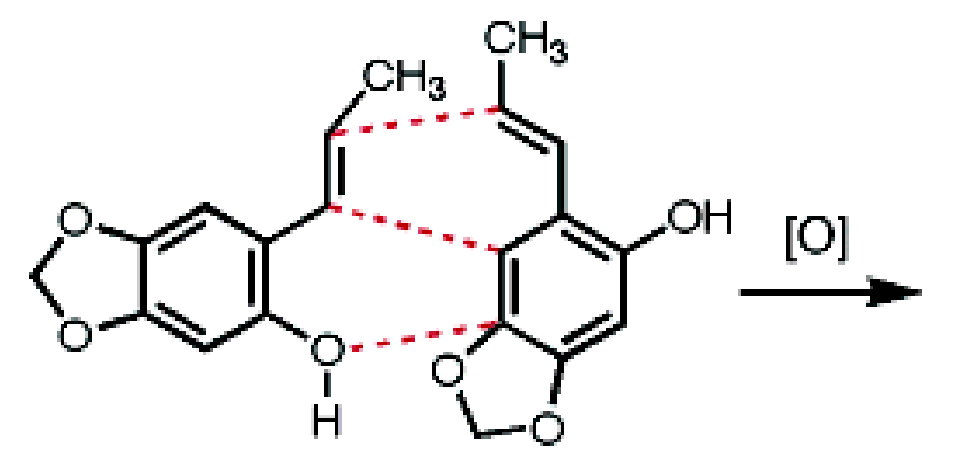

monomers<smiles></smiles>

carpanone

Scheme 1. 
<smiles></smiles><smiles>[R7]O[R7]c1ccccc1CCC[C@H]1C=C2C(=O)C=C[C@]3(O)Oc4ccc(C(=O)NCc5ccccc5)cc4[C@]2(C)[C@@H]1[C@@H]3C</smiles>

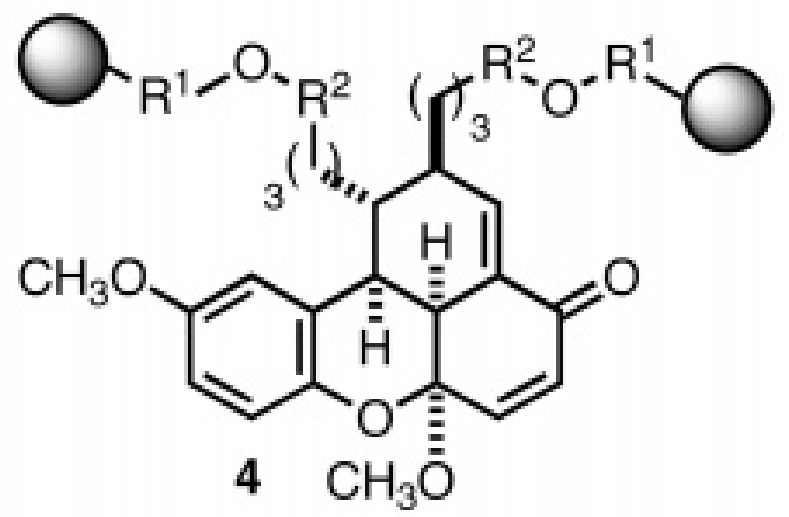

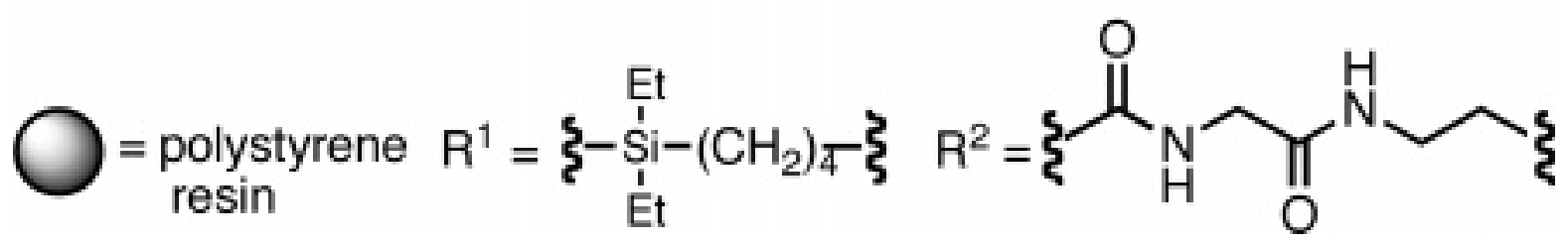

Scheme 2. 

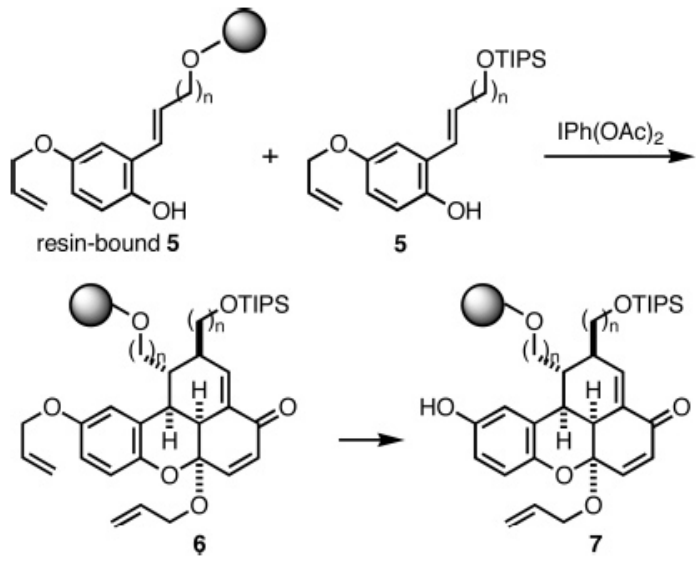

Scheme 3. 

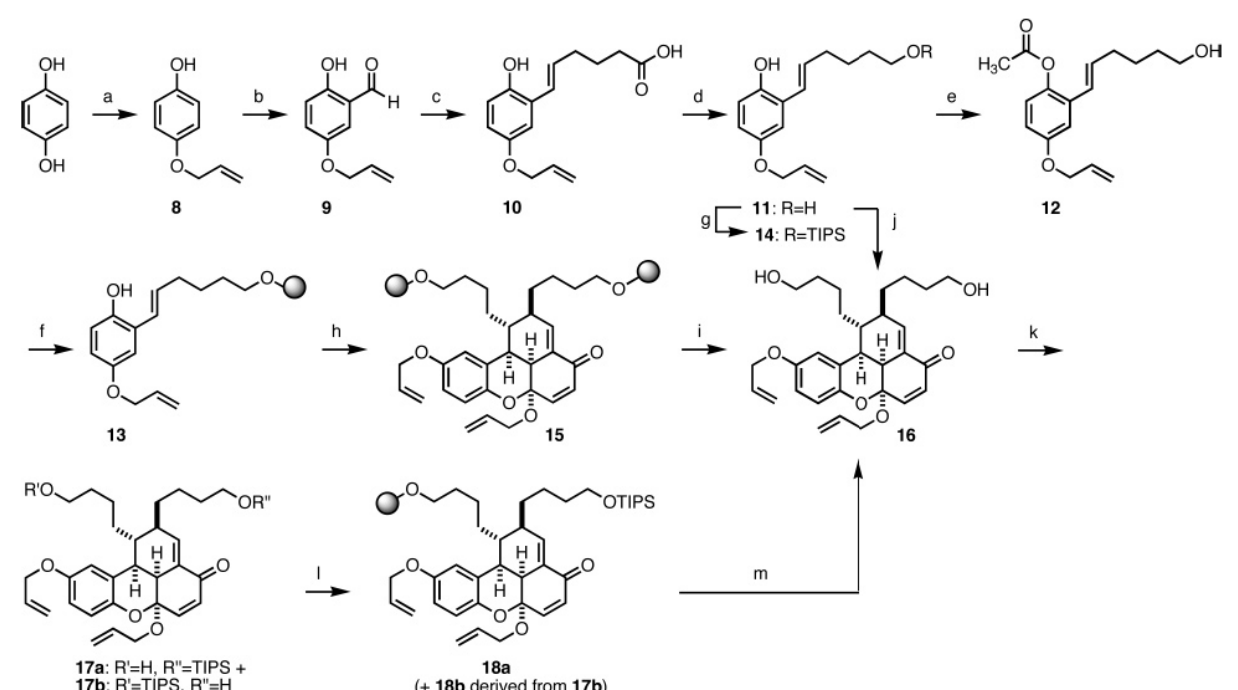

Conditions: (a) (i) $\mathrm{LiH}, \mathrm{DMF}, 0^{\circ} \mathrm{C}$, (ii) allyl bromide, $36 \%$; (b) $\mathrm{NaOH}, \mathrm{CHCl}_{3}, \mathrm{H}_{2} \mathrm{O}$, reflux, $56 \%$; (c) $\mathrm{LiN}\left(\mathrm{TMS}_{2}\right.$, 4-carboxybutyltriphenylphosphonium bromide, THF, $0{ }^{\circ} \mathrm{C}, 65 \%$; (d) $\mathrm{LAH}, \mathrm{THF},-78{ }^{\circ} \mathrm{C}, 75 \%$; (e) NaOH, 1 -acetyl-1 $1 \mathrm{H}-1,2,3$-triazolo 44,5 -b]-pyridine, THF, $84 \%$; (f) (i) $5 \%$ TfOH, diisopropylp-methoxyphenylsilyl resin, $\mathrm{CH}_{2} \mathrm{Cl}_{2}$, (ii) 12, (iii) piperidine, THF; (g) TIPSCl, imidazole, DMF, $8 \%^{\circ} \%^{\circ}$; (h) $\mathrm{Phl}(\mathrm{OAc})_{2}$, $\mathrm{F}_{6}-\mathrm{IPA}_{1}, 14, \mathrm{CH}_{2} \mathrm{Cl}_{2}$; (i) (i) $\mathrm{HF} \cdot$ pyridine, THF, (ii) $\mathrm{TMSOCH}_{3}, 50 \%$; (j) $\mathrm{PhI}(\mathrm{OAc})_{2}, \mathrm{CH}_{2} \mathrm{Cl}_{2}, 0{ }^{\circ} \mathrm{C}, 60 \%$; (k) $\mathrm{TIPSCl}$, imidazole, DMF, $46 \%$; (1) (i) $5 \% \mathrm{TfOH}$, diisopropyl-p-methoxyphenylsilyl resin, $\mathrm{CH}_{2} \mathrm{Cl}_{2}$, (ii) $17 \mathbf{a} / \mathbf{b}$; (m) (i) $\mathrm{HF} \cdot$ pyridine, THF, (ii) $\mathrm{TMSOCH}_{3}, 90 \%$.

Scheme 4a. 
<smiles>C/C=C/c1cc2c(cc1O)OCO2</smiles>

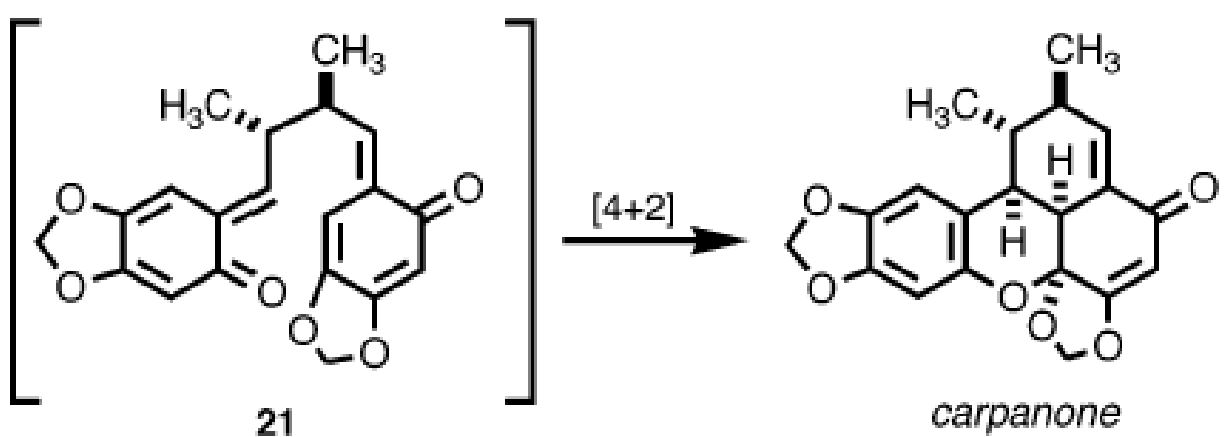

(b)

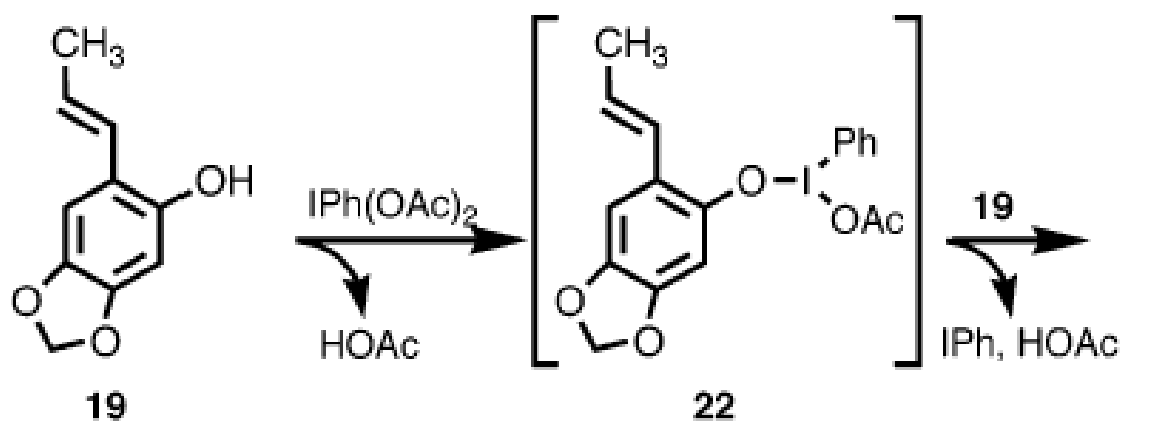

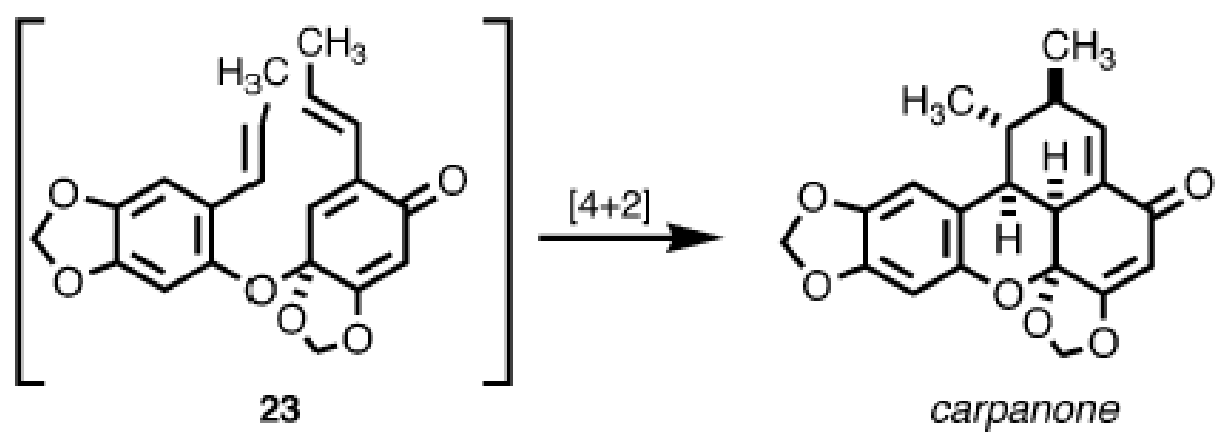

Scheme 5. 
<smiles>C=CCOc1ccc(O)c(/C=C/C)c1</smiles>

24

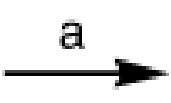

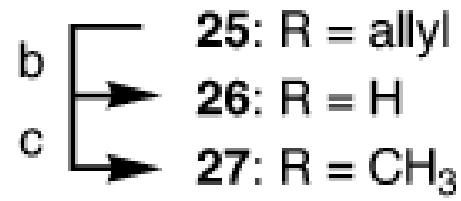

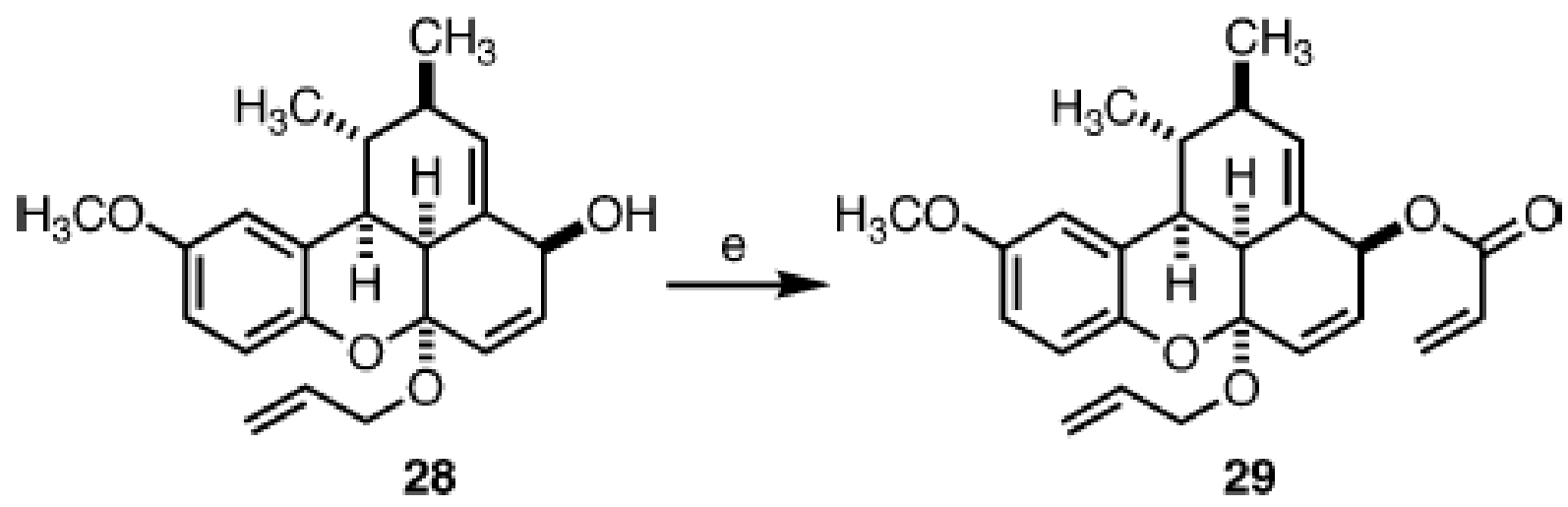

${ }^{a}$ Conditions: (a) $\mathrm{PhI}(\mathrm{OAc})_{2}, \mathrm{CH}_{2} \mathrm{Cl}_{2}, 0{ }^{\circ} \mathrm{C} 55 \%$; (b) $\mathrm{Pd}\left(\mathrm{PPh}_{3}\right)_{4}$, sodium 2-ethylhexanoate, $\mathrm{CH}_{2} \mathrm{Cl}_{2}, 40 \%$; (c) $\mathrm{Cs}_{2} \mathrm{CO}_{3}, \mathrm{CH}_{3} \mathrm{I}, \mathrm{DMF}, 0^{\circ} \mathrm{C}, 85 \%$; (d) $\mathrm{CeCl}_{3} \cdot 7 \mathrm{H}_{2} \mathrm{O}, \mathrm{NaBH}_{4}, \mathrm{CH}_{3} \mathrm{OH}, 0{ }^{\circ} \mathrm{C}, 95 \%$; (e) acrylic acid, $\mathrm{Et}_{3} \mathrm{~N}, \mathrm{EDC}$, DMAP, $\mathrm{CH}_{2} \mathrm{Cl}_{2}, 0^{\circ} \mathrm{C}, 74 \%$.

Scheme 6a. 

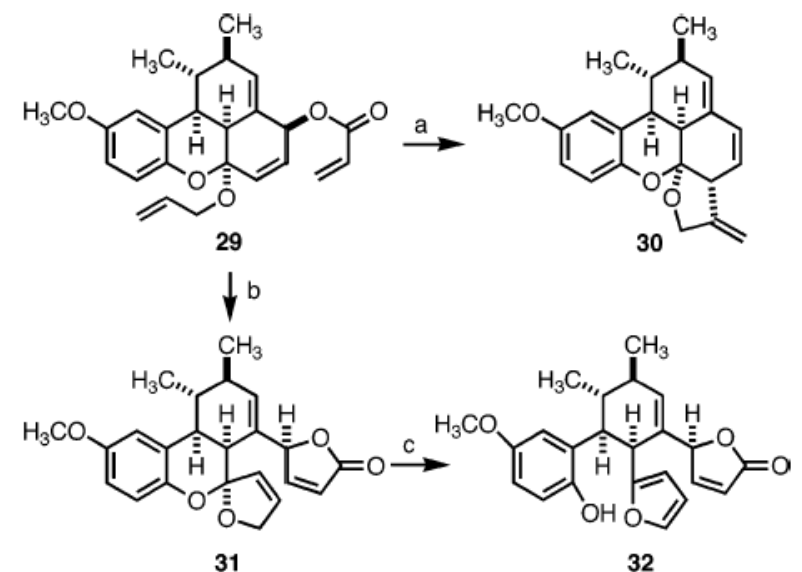

${ }^{a}$ Conditions: (a) $\mathrm{Pd}(\mathrm{OAc})_{2}, \mathrm{Ag}_{2} \mathrm{CO}_{3}, \mathrm{PPh}_{3}, \mathrm{CH}_{3} \mathrm{CN}, 60{ }^{\circ} \mathrm{C}$, dark, $96 \%$;

(b) (dihydroimidazolylidene) $\mathrm{RuCl}_{2}\left(\mathrm{PCy}_{3}\right)=\mathrm{CHPh}$, benzene, $55{ }^{\circ} \mathrm{C}, 74 \%$;

(c) $\mathrm{HCl}, \mathrm{CH}_{3} \mathrm{OH}, 0^{\circ} \mathrm{C}, 74 \%$.

Scheme 7a. 


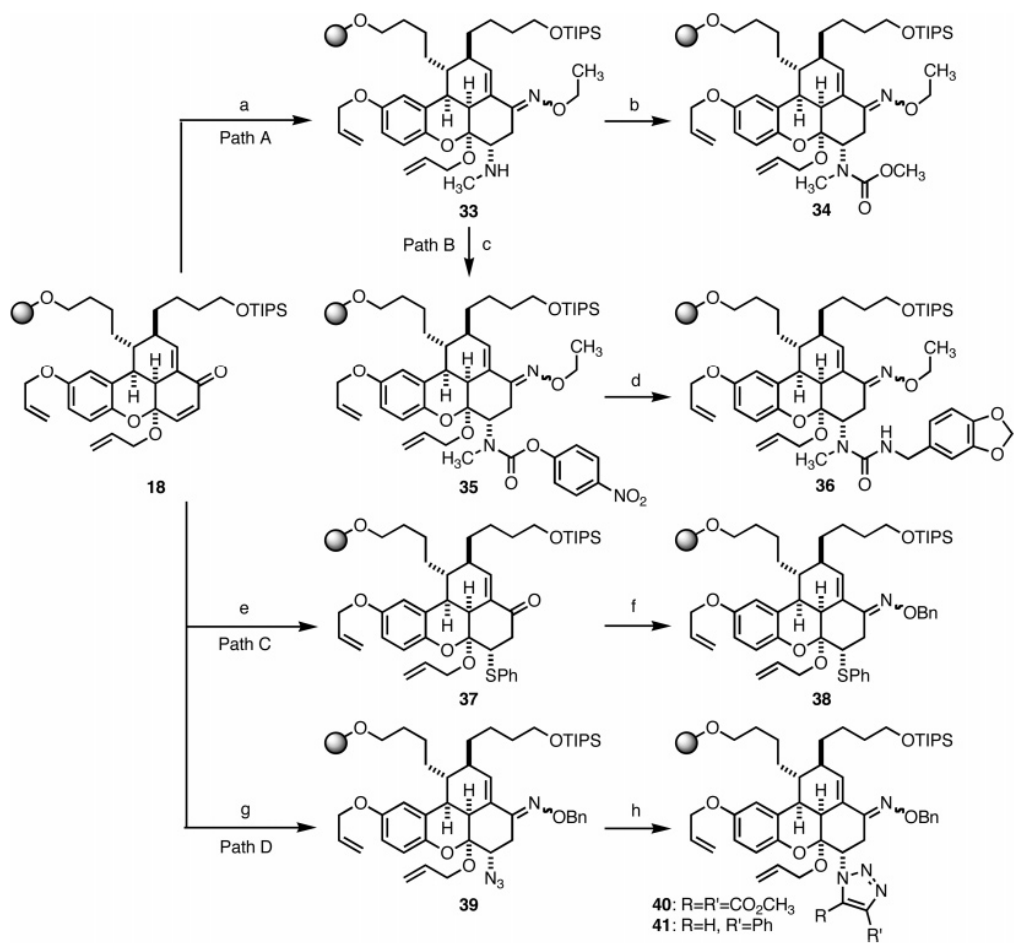

${ }^{a}$ Conditions: (a) $o$-EtONH $2 \cdot \mathrm{HCl}, \mathrm{Et} 3 \mathrm{~N}, \mathrm{CH}_{3} \mathrm{NH}_{2}, p$ - $\mathrm{TsOH}, \mathrm{CH}_{3} \mathrm{OH}, \mathrm{CH}_{2} \mathrm{Cl}_{2}, 72 \mathrm{~h}$; (b) methyl chloroformate, 2,6-lutidine, THF, $5 \mathrm{~h}$; (c) $p$-nitrophenyl chloroformate, 2,6-lutidine, THF, $5 \mathrm{~h}$; (d) piperonylamine, THF, DMSO, $60{ }^{\circ} \mathrm{C}, 48 \mathrm{~h}$; (e) $\mathrm{PhSH}, \mathrm{Et}_{3} \mathrm{~N}, \mathrm{THF}, 18 \mathrm{~h} ;$ (f) $o-\mathrm{BnONH}_{2} \cdot \mathrm{HCl}, \mathrm{Et}{ }_{3} \mathrm{~N}, p-\mathrm{TsOH}$ $\mathrm{CH}_{3} \mathrm{OH}, \mathrm{CH}_{2} \mathrm{Cl}_{2}, 12 \mathrm{~h} ;(\mathrm{g}) o-\mathrm{BnONH}_{2} \cdot \mathrm{HCl}_{1} \mathrm{Et}_{3} \mathrm{~N}, \mathrm{TMSN}_{3}, \mathrm{AcOH}, \mathrm{CH}_{3} \mathrm{OH}, \mathrm{CH}_{2} \mathrm{Cl}_{2}, 12 \mathrm{~h}$; (h) for 40 , dimethylacetylene dicarboxylate, $\mathrm{THF}, 60^{\circ} \mathrm{C}, 8 \mathrm{~h}$; for 41, phenylacetylene, Cul, DIPEA, THF, $60^{\circ} \mathrm{C}, 12 \mathrm{~h}$

\section{Scheme 8a.}




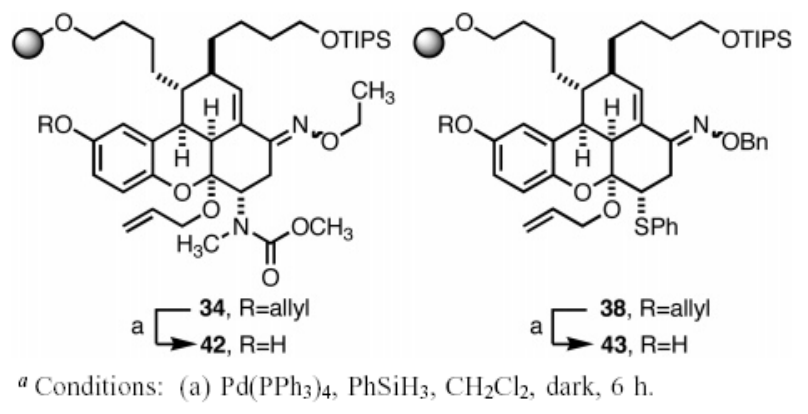

Scheme 9a. 


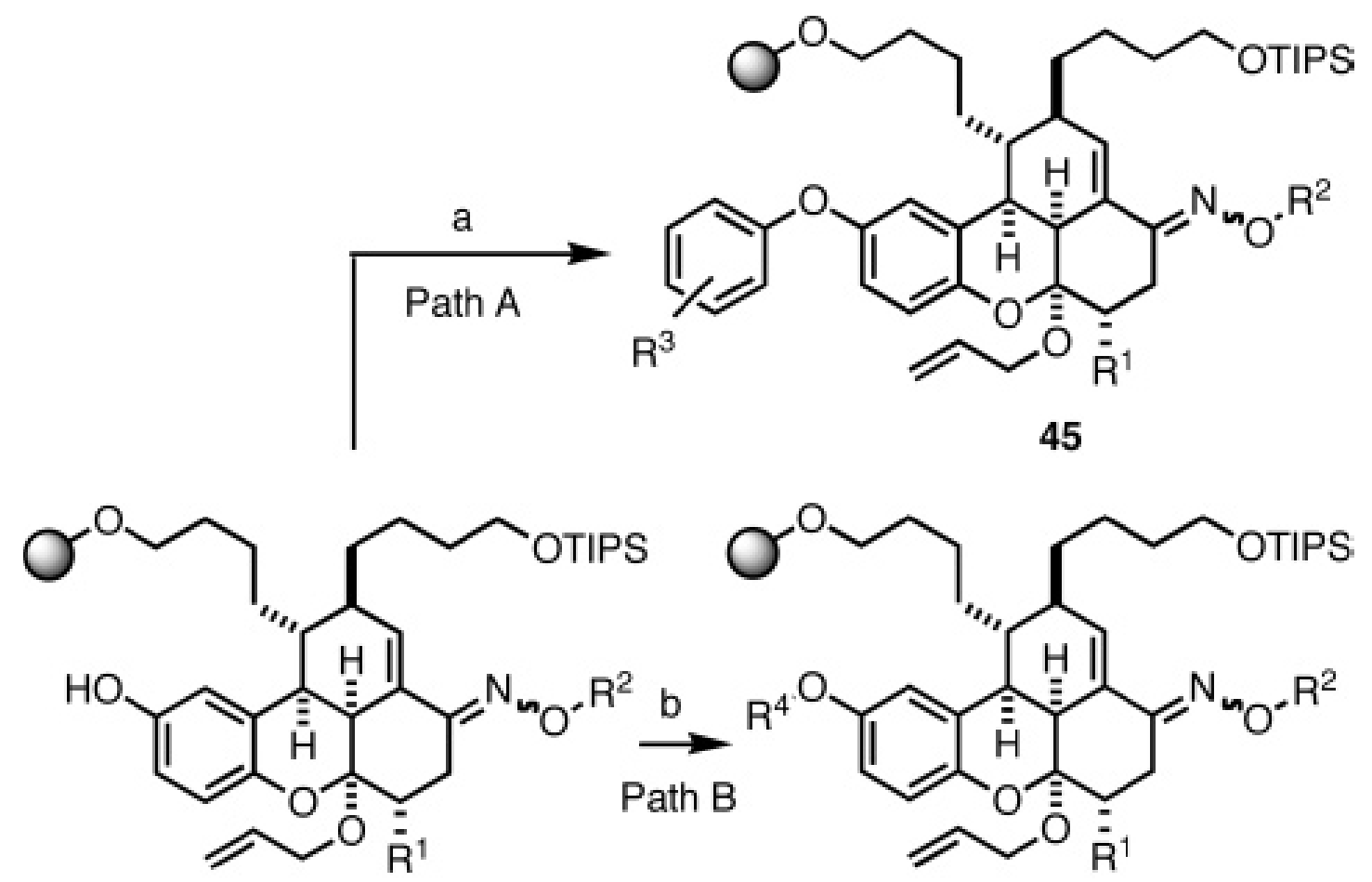

44

46

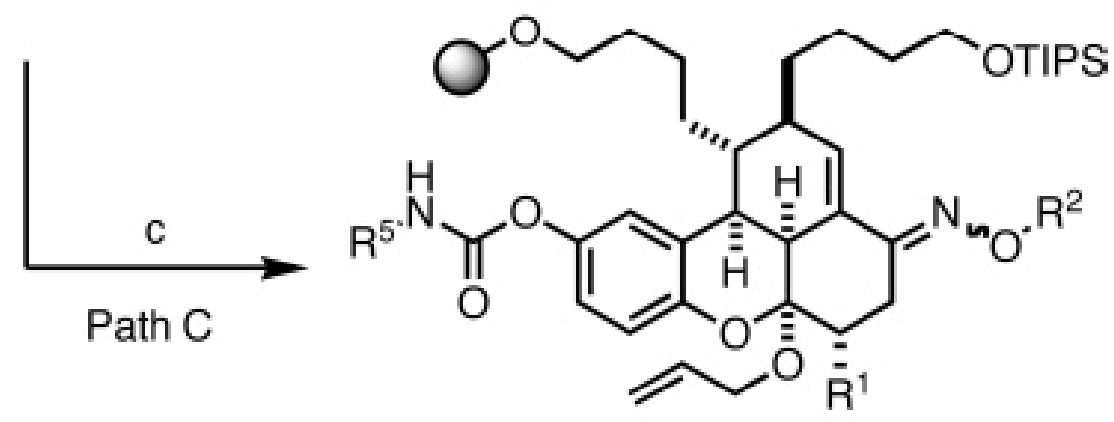

47

${ }^{a}$ Conditions: (a) $\mathrm{R}^{3}-\mathrm{ArOH}, \mathrm{Cu}(\mathrm{OAc})_{2}, \mathrm{Et}_{3} \mathrm{~N}, 4 \AA \mathrm{m} . \mathrm{s} ., \mathrm{CH}_{2} \mathrm{Cl}_{2}, 48$ h; (b) $\mathrm{PPh}_{3}, \mathrm{DIAD}, \mathrm{R}^{4}-\mathrm{OH}, \mathrm{CH}_{2} \mathrm{Cl}_{2}$, dark, $48 \mathrm{~h}$; (c) $\mathrm{R}^{5}-\mathrm{NCO}, \mathrm{Et}_{3} \mathrm{~N}, \mathrm{CH}_{2} \mathrm{Cl}_{2}$, $48 \mathrm{~h}$.

Scheme 10a. 


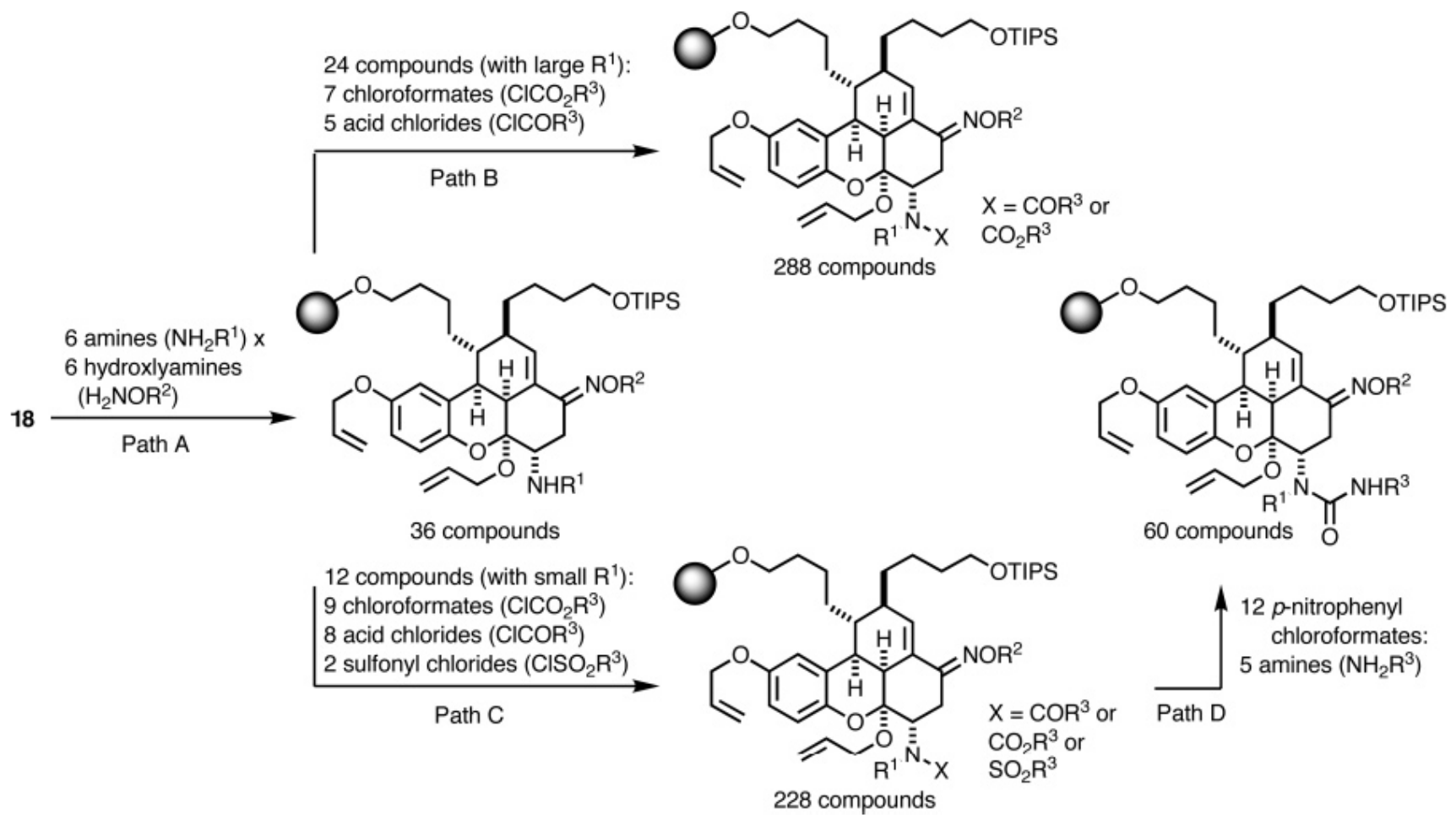

Scheme 11. 


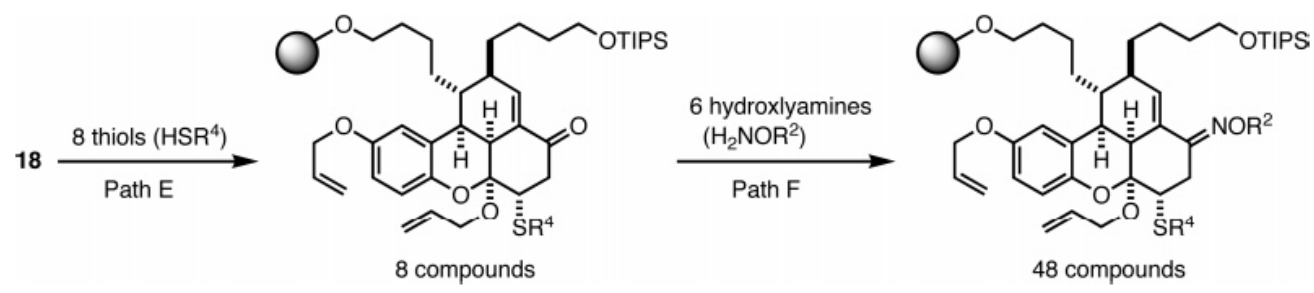

Scheme 12. 

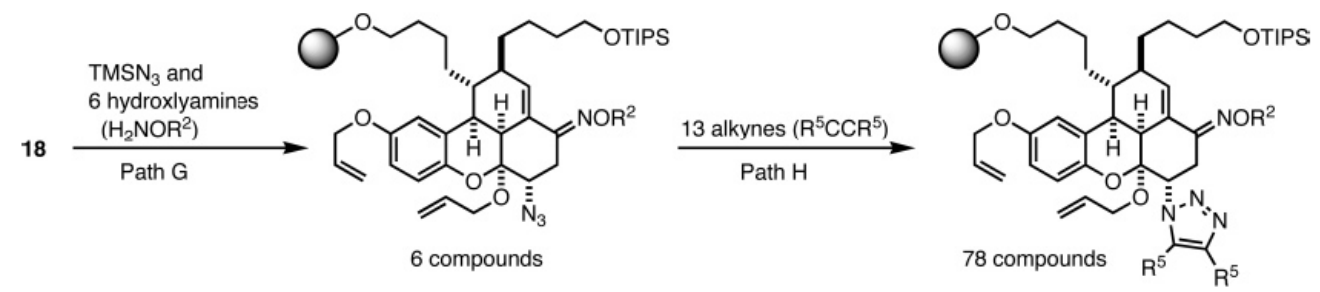

Scheme 13. 


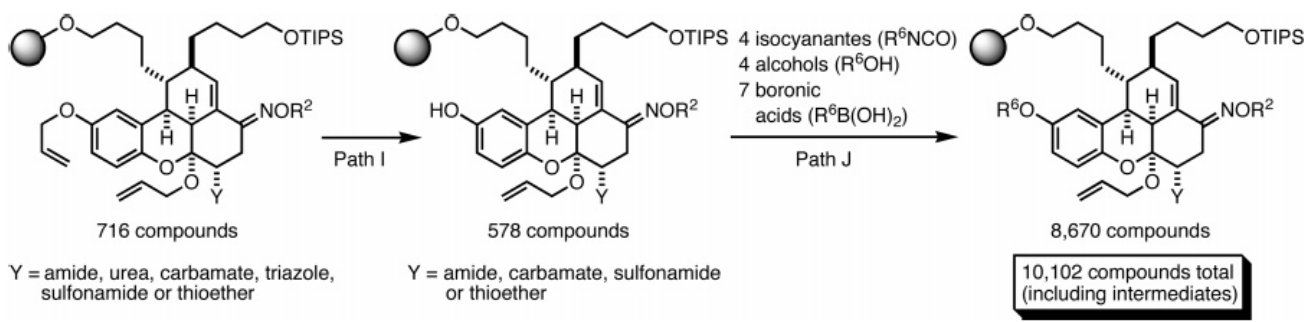

Scheme 14. 


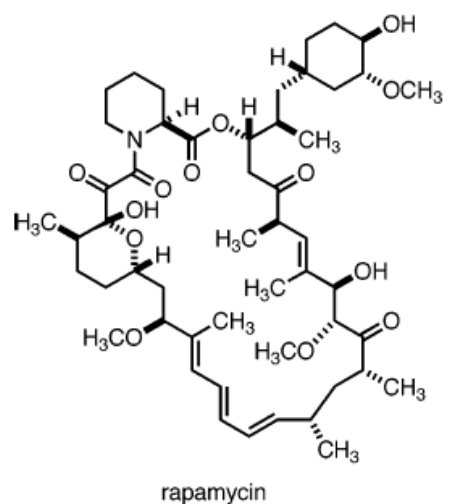

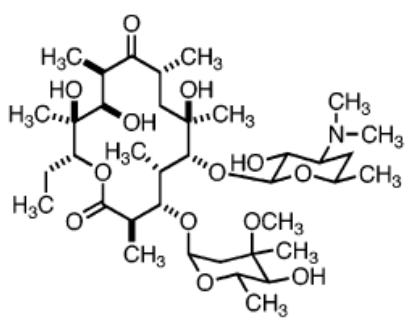

erythromycin

antibiotic

inhibits bacterial ribosome

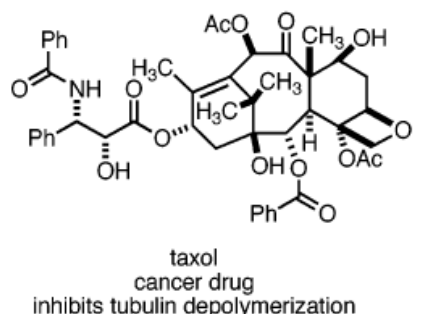<smiles>CCC(C)C(=O)C[C@H]1CC[C@H](C)C=C2C=CC(C)C(CC[C@]3(C)CC(O)CC(=O)O3)C21</smiles>

lovastatin anticholesterol drug inhibits HMGCOA probe of mTOR biology<smiles>C[C@H]1CCC/C=C/[C@H]2C[C@@H](O)C[C@H]2[C@H](O)/C=C/C(=O)O1</smiles>

brefeldin A

dismantles Golgi apparatus

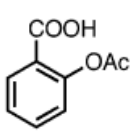

aspirin

anti-inflammatory drug inhibits prostaglandin synthesis

Chart 1.

Natural Products and Their Derivatives Used as Medicines or to Probe Biology 
Amines:

(c)

Hydroxylamines:

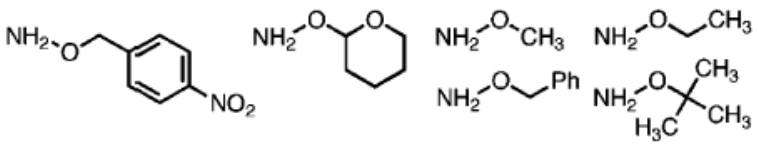

Thiols:

-SH

$\longrightarrow-\mathrm{SH}$ AcHN

$\Longrightarrow-\mathrm{SH}$

Chloroformates:

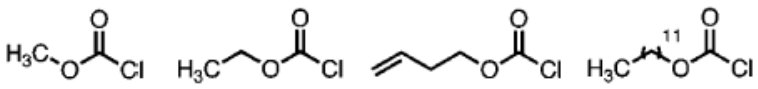

$\mathrm{Cl} \sim_{\mathrm{Cl}}$

等

Amines (ureas):

$\mathrm{C}_{\mathrm{N}}^{\mathrm{N}} \underbrace{\mathrm{NH}_{2}}_{\mathrm{O}}$

Sulfonyl chlorides:

(1)
Acyl chlorides:<smiles>COc1cccc(CC(=O)Cl)c1</smiles>

Alkynes:

$\mathrm{EtO}_{2} \mathrm{C}=\mathrm{CO}_{2} \mathrm{Et} \quad \mathrm{Bu}^{\mathrm{t}} \mathrm{O}_{2} \mathrm{C}=\mathrm{CO}_{2}{ }^{\mathrm{t}} \mathrm{Bu} \quad \mathrm{H}_{3} \mathrm{CO}_{2} \mathrm{C}=\mathrm{H}$

$\mathrm{H}_{3} \mathrm{CO}_{2} \mathrm{C}=\mathrm{CO}_{2} \mathrm{CH}_{3} \quad \mathrm{Bu}_{2} \mathrm{C}=\mathrm{H} \quad \mathrm{TMSO}_{2} \mathrm{C}=\mathrm{H}$

$\mathrm{TMSO}_{2} \mathrm{C}=\mathrm{CO}_{2} \mathrm{TMS} \quad{ }^{\mathrm{TMSO}}=\mathrm{H}$

$\mathrm{H}_{3} \mathrm{C}=\mathrm{H} \quad{ }_{\mathrm{EtO}}^{\mathrm{EtO}}=\mathrm{H} \quad \mathrm{Cl}=-\mathrm{H}$

(1) $=\mathrm{H}$

Alcohols:

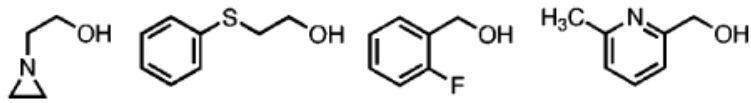

Isocyanates:

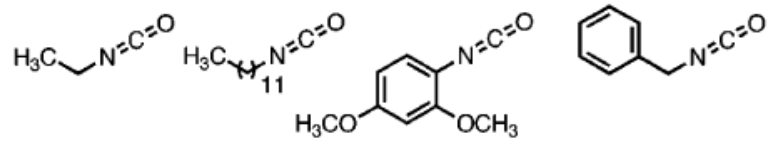

Aryl boronic acids:

(N)

$\underbrace{\mathrm{B}(\mathrm{OH})_{2}}_{\mathrm{CHO}}$

Chart 2.

Compilation of Building Blocks Used in the Library Synthesis 